DEPARTMENT OF FOOD AND RESOURCE ECONOMICS

UNIVERSITY OF COPENHAGEN

IFRO Working Paper

An alternative to the standard spatial econometric approaches in hedonic house price models

Kathrine Lausted Veie Toke Emil Panduro 


\section{IFRO Working Paper 2013 / 18}

An alternative to the standard spatial econometric approaches in hedonic house price models Authors: Kathrine Lausted Veie, Toke Emil Panduro

$\underline{\text { www.ifro.ku.dk/english/publications/foi series/working papers/ }}$

Department of Food and Resource Economics (IFRO)

University of Copenhagen

Rolighedsvej 25

DK 1958 Frederiksberg DENMARK

www.ifro.ku.dk 


\title{
An alternative to the standard spatial econometric approaches in hedonic house price models
}

\author{
Kathrine Lausted Veie*and Toke Emil Panduro ${ }^{\dagger}$
}

\begin{abstract}
Hedonic models are subject to spatially correlated errors which are a symptom of omitted spatial variables, misspecification or mismeasurement. Methods have been developed to address this problem through the use of spatial econometrics or spatial fixed effects. However, often spatial correlation is modeled without much consideration of the theoretical implications of the chosen model or treated as a nuisance to be dealt with holding little interest of its own. We discuss the limitations of current standard spatial approaches and demonstrate, both empirically and theoretically the generalized additive model as an alternative. The generalized additive model is compared with the spatial error model and the fixed effects model. We find the generalized additive model to be a solid alternative to the standard approaches, having less restrictive assumptions about the omitted spatial processes while still being able to reduce the problem of spatial autocorrelation and provide trustworthy estimates of spatial variables. However, challenges connected with spatially varying data remain. The choice of flexibility in the spatial structure of the model affects estimated parameters of some spatially varying characteristics markedly. This suggests that omitted variable bias may remain an important problem. We advocate for an increased use of sensitivity analysis to determine robustness of estimates to different models of the (omitted) spatial processes.
\end{abstract}

\section{Introduction}

The hedonic model as described by Rosen (1974) remains popular in the environmental valuation literature. One major concern in hedonic estimation is the issue of omitted variable bias and spatially correlated errors. Spatial correlation in the error term is a common finding in applied hedonic analysis and can be caused by misspecification of spatially delineated variables, systematic mismeasurement of the spatial regressors or spatial covariates omitted from the model. The existence of spatially correlated errors can result in inconsistent and inefficient parameter estimates depending on the underlying cause (Anselin, 2010). Recent years have seen many improvements in the way such omitted variables are addressed. However, in a special issue of the Journal of Regional Science, Gibbons and Overman (2012) and McMillen (2012) criticize the "automatic" use of spatial lag and spatial error components in econometric modeling. Brady and Irwin (2011) discuss developments in land use modeling in the light of this recent critique. We focus our attention on hedonic house price models and the challenge of handling the spatial dimension in these models. In addition we present an alternative approach to modeling the spatial dimension of the housing market in the form of a spatial generalized additive model.

In the current hedonic literature, attempts to reduce spatial correlation in the error term are made using different methods with different interpretations of the character spatial correlation. To the best of

\footnotetext{
*kave@life.ku.dk, University of Copenhagen

† tepp@life.ku.dk, University of Copenhagen
} 
our knowledge there are no surveys which explicitly contain a critical review of the use of spatial methods in hedonic house price modeling. However, Kuminoff et al. (2010) discuss the choice of functional form for hedonic estimation in the light of the increased use of fixed effects or spatial econometrics which aims to reduce omitted variable bias. Looking at more than 60 published papers, they find that more than half of the hedonic studies apply either spatial fixed effects or spatial econometric models to address omitted spatial variables. We looked at 21 hedonic studies published since 2010 in the Journal of Environmental Economics and Management, Land Economics, Ecological Economics and Environmental and Resource Economics. Approximately half of these studies used either a spatial error term or a spatial lag term to control for spatial correlation while the other half used fixed effects and differences-in-differences. As such it is clear that the use of these methods is extensive in current hedonic research. The specification of spatial econometric models varies across studies both with regard to the chosen model (spatial lag, spatial error or both) and the design of the spatial weight matrix (inverse distance weighting, contiguity etc.). Similarly, fixed effects are generally based on available spatial entities such as provinces, census blocks etc. Only two of the papers (Heintzelman and Tuttle (2012), Chamblee et al. (2011)) contained in-depth discussion of the choice of spatial controls and explicitly discuss sensitivity analysis of different spatial specifications.

The aim of this paper is to address the strengths and weaknesses of the standard econometric strategies to handle spatial autocorrelation applied in the literature on hedonic house price valuation. On the basis of this discussion, we suggest an alternative spatial model, a spatial Generalized Additive Model (GAM), which handles omitted spatial processes non-parametrically. To our knowledge the use of a GAM for explicit spatial modeling is novel to the peer reviewed hedonic house price literature. The only similar application of a GAM that we are aware of is in a book chapter by Geniaux and Napoleone (2008). However, their emphasis is different as they focus on comparison with a geographically weighted regression. They do not consider parametric spatial models or fixed effects both of which are more commonly used in the hedonic literature. The present paper is divided into two parts. In the first part we provide a general discussion of the standard econometric approaches and introduce the GAM model as a strong alternative. In the second part we illustrate the discussion using an empirical application. We estimate the hedonic price function using a simple linear model with no spatial corrections, a Spatial Error Model (SEM), a spatial fixed effect model and a GAM model. We then vary the choice of weight matrix and the number of basis functions to evaluate the sensitivity of our results to the scale of the spatial control.

Our main critique of the fixed effect and spatial econometric approaches is that the nature of the omitted spatial processes is assumed to be known when in fact it is not. In practice there are likely to be several omitted spatial processes at different spatial scales in the housing market. In the fixed effect model a geographical entity such as a school district or another spatial subdivision is assumed to capture the unknown omitted spatial processes. In the standard spatial econometric models, e.g. spatial error and spatial lag models, the spatial processes are assumed to be captured by a spatial weight matrix which is often based on the 10 or 20 nearest neighbors. We argue that it is inappropriate to place such restrictions on the omitted spatial processes. In contrast, the GAM does not require any assumptions about the structure of the omitted spatial processes in the housing market. The spatial processes are handled by letting the geographical coordinates of each property enter into the model through a smooth function based on thin plate splines. In practice, the spatial GAM can be understood as a smooth fixed effect as opposed to the standard discrete version of the fixed effect model.

The most commonly used parametric spatial econometric approaches have some additional drawbacks. The SEM is based on the assumption that the correlation in the error term is a result of processes which are 
not correlated with the variables in the model. In that setting, the correlation in residuals would only lead to inefficient estimates and biased standard errors, which the SEM corrects for. In contrast, the GAM and the fixed effect model treat the omitted spatial processes as an additional regressor. The model specification in a spatial lag model implies the existence of a spatial multiplier effect of the marginal values of the model (Lesage and Pace, 2009). Such an effect seems unjustified in hedonic house price models when interpreting the marginal change in prices as a measure of an individual household's willingness to pay.

When comparing the spatial GAM with alternative approaches and varying the dimension of spatial modeling, we find that estimated coefficients of spatially varying regressors can be highly sensitive to the way in which the spatial dimension is modeled. The results in our example are largely robust for the structural housing characteristics. However, parameter estimates of several spatially varying regressors turn out to be sensitive to the level of spatial correction and the model estimated. We hypothesize that this sensitivity of parameters to different approaches to handling omitted spatial processes indicates that substantial risk of omitted variable bias in the hedonic model remains despite the use of spatial models. The severity of potential bias can be assessed by carrying out sensitivity analysis with different spatial models. We conclude that spatial sensitivity analysis should be a part of every hedonic study with spatially varying regressors.

\section{Modeling the value of a residence}

Housing is a composite good and its price reflects its composition. A house in a more attractive location with many amenities tends to be more expensive than a house with fewer amenities all else equal. For this reason, the transactions in the housing market can be used to place a value on many amenities not traded independently in the market, see Palmquist (2004) for an introduction to the literature. The hedonic method is based on analyzing the equilibrium price in the housing market under the assumption that a continuum of housing types exists. The equilibrium price schedule is determined by the structure of preferences and technologies in the market and can be expressed as a function of the attributes of the house ${ }^{1}$ :

$$
P=f(X)
$$

Housing attributes, $X$, usually include structural variables such as the number of rooms, the size of the living area and the time of construction, as well as accessibility measures such as distance to the central business district or distance to train stations or highway access. The housing good further has different environmental attributes such as traffic noise exposure (Day et al. (2007)), air quality (Chay and Greenstone (2005)), green space (Abbott and Klaiber (2010a)) as well as neighborhood characteristics such as school quality, crime levels etc. Household utility is a function of consumption of housing, $H(X)$ and other goods, $C$ :

$$
U=g(H(X), C)
$$

The household chooses a quantity of housing attribute, $X$, to maximize utility subject to a budget constraint: $M=P(X)+C$, where non-housing consumption, $\mathrm{C}$, is the numeraire. Maximizing utility delivers the following first order condition:

\footnotetext{
${ }^{1}$ This is the first stage of the hedonic method, where an equilibrium house price schedule is estimated to reveal a household's marginal willingness to pay for a characteristic. The second stage of the hedonic analysis, where household preferences are recovered, is not discussed in this paper.
} 


$$
\frac{\partial U}{\partial X_{j}} / \frac{\partial U}{\partial C}=\frac{\partial P}{\partial X_{j}}
$$

Utility maximization implies that the change in utility resulting from a marginal increase in $X_{j}$ exactly equals the change in the house price following the same increase in $X_{j}$ all else equal ${ }^{2}$. Based on equation 2.1, the marginal price of a housing attribute is defined as the partial derivative of the house price with respect to the characteristic:

$$
\frac{\partial P}{\partial X_{j}}=f_{j}(x)
$$

The main object of most published hedonic analyses is the recovery of (average) marginal prices sometimes also referred to as implicit prices. Only a few studies proceed to recover household preferences, as this is subject to several econometric challenges, see Epple (1987), Kahn and Lang (1988) and Ekeland et al. (2004) for further discussion. The marginal prices can be used to valuate marginal changes in e.g. environmental amenity levels. For larger changes in amenities, the marginal price can be a poor estimate of the change in welfare.

\subsection{Applying the method}

The unit of analysis in most hedonic studies is the individual transacted dwelling. With the use of Geographical Information Systems, researchers have access to ample data on the location and surroundings of dwellings. However, it remains close to impossible to measure every characteristic of a home and a neighborhood. Location is often described using proximity measures or similar proxies for accessibility to amenities. Such proxies may not always be an accurate reflection of the household's perception of the amenity. Further, it is not clear how different attributes should enter the hedonic price function. Theory gives little guidance as to the shape of the hedonic price schedule is determined by the preference parameters and technology parameters together, see Ekeland et al. (2004) for an excellent discussion. Environmental amenity access, general accessibility and neighborhood characteristics all vary with location. Variables measuring these housing attributes therefore tend to be spatially delineated, which in turn implies that they tend to be highly correlated across observations close to each other in space. Misspecification or mismeasurement of such spatially delineated variables can result in spatial autocorrelation in the model residuals, and potentially, biased parameter estimates (Anselin and Lozano-Gracia, 2008). The same results if a spatial regressor is omitted from the analysis or measured with (systematic) error. Take the hedonic model written below, where - for simplicity - two spatially delineated attributes $X_{1}$ and $X_{2}$ determine the price of the house and $\epsilon$ is a random i.i.d. error term:

$$
P=X_{1} \beta_{1}+X_{2} \beta_{2}+\epsilon
$$

Suppose that $X_{1}$ and $X_{2}$ are uncorrelated and linear related to $\mathrm{P}$, and $X_{2}$ is wrongly specified with a $\log$ transformation. When estimating the hedonic equation, we will find $P=X_{1} \hat{\beta}_{1}+\ln \left(X_{2}\right) \hat{\beta}_{2}+\hat{u}$, where $\hat{u}=\epsilon+X_{2} \beta_{2}-\ln \left(X_{2}\right) \hat{\beta}_{2}$, which will vary across space as $X_{2}$ varies across space. If $X_{2}$ is omitted from the analysis, the error will consist of $\hat{u}=X_{2} \beta_{2}+\epsilon$. Finally, if $X_{2}$ has been mismeasured, so the model is estimated with $\tilde{X}_{2}=X_{2}+e$, then the error term consists of $\hat{u}=\epsilon-e \hat{\beta}_{2}$. The estimated coefficient $\hat{\beta}_{2}$ will be

\footnotetext{
${ }^{2}$ It is an underlying assumption in hedonic theory that the housing market contains a continuum of houses, such that any combination of attributes can be found. When this is not the case, the equality may not hold as households may have preferred to have more or less of an attribute at the given "marginal price" than was available.
} 
biased towards zero, if the error is uncorrelated with true $X_{2}$. In that case, there may be no resulting spatial autocorrelation. However, if the measurement error is also correlated with $X_{2}$, the bias will depend on the sign and size of the correlation, and in addition, the error term $\hat{u}$ will be spatially correlated. Additionally, measurement error can be inherently spatial, e.g. if it arises from interpolation of variables only measured at discrete points (e.g. air pollution data). If the data is interpolated without attention to, e.g. wind direction or barriers in the landscape, the result would be a spatially correlated measurement error. We refer to all three causes of spatial correlation as "omitted spatial processes".

The preceding discussion assumes that $X_{1}$ and $X_{2}$ are uncorrelated. However, spatially delineated regressors are often correlated. Homes near the central business district tend to be far from natural areas or agricultural fields, while industry is often located near waterways or other infrastructure. Through the development of the urban landscape, locational attributes will therefore tend to correlate with each other to varying degrees. When this is the case, it is not unlikely that mismeasurement, misspecification or omission of a spatially delineated variable can bias parameter estimates of other spatially varying regressors in the model as well as the parameter estimate of the affected variable. In practice, there are likely to be several omitted spatial processes in a hedonic data set which vary at different scales. As environmental amenities tend to be inherently spatial in nature, omitted spatial processes are particularly troubling in the hedonic valuation literature. Our main focus here lies on methods intended to aid in the recovery of robust marginal prices for spatially delineated attributes. In the following, we discuss the techniques most commonly used in the literature.

\subsection{Spatial econometrics}

In spatial econometrics spatial relationships are modeled parametrically through the use of weight matrices identifying the relevant neighboring observations. There are several different varieties with the most common being the SEM, the spatial lag model, and the combined model containing both spatial error and spatial lag processes. These spatial econometric models impose strong assumptions about the structure of spatial correlation in the data. A general spatial autoregressive model with spatial autoregressive errors (SARAR(1,1)) for the price of a house, $P$, is given by:

$$
P=X \beta+\rho W_{p} P+u
$$

where

$$
u=\lambda W_{u} u+\epsilon
$$

The matrices $W_{p}$ and $W_{u}$ are usually referred to as the spatial weight matrices and often coincide in applications. The diagonal elements are all zero and off-diagonal elements can be ones (contiguity indicators) or a function of distance between observations. In practice, the weight matrices are row standardized, so the term $\rho W_{p} P$ corresponds to a weighted average price of neighboring observations. The parameters $\lambda$ and $\rho$ are commonly known as the autocorrelation coefficients. Intuitively, the autocorrelation coefficients will be positive in most house price analyses reflecting clustering in high and low value (residential) areas. In the SEM, $\rho=0$, and in the spatial lag model, $\lambda=0$, so that the errors, $u$, are independent and identically distributed. The researcher usually chooses the relevant dimension of the weight matrix, i.e. how many neighbors to include or which distance boundary to set for neighborhood effects. This choice is made either based on tests, e.g. Moran's I test for spatial correlation, or justified by referring to the existing literature. 
A notable exception is the SEM in Hoshino and Kuriyama (2010) where the relevant distance is estimated.

Autocorrelation in the error term is sometimes considered to affect inference through incorrect standard errors. When errors are positively correlated across space, failure to account for this correlation can lead to overestimating significance levels. Standard errors of estimated parameters tend to be underestimated in ordinary least squares estimation when errors are clustered. If spatial correlation derives from omitted spatial components correlated with regressors included in the model, the estimated parameters will additionally be biased. Spatially delineated amenities tend to be correlated with each other and hence also with omitted or misspecified spatial characteristics. This is due to the fact that location typically varies only in two dimensions (longitude, latitude). Therefore the conditions under which the SEM is valid are not likely to be satisfied in many housing market applications. Essentially, the SEM is similar to the use of random effects in panel data estimation or feasible generalized least squares. McMillen (2012) emphasizes that the SEM is also a form of spatial smoother, where the number of neighbors plays a role similar to the choice of bandwidth in terms of kernel smoothing or basis dimension in terms of splines. ${ }^{3}$

The spatial lag model in turn implies that there exist direct spillover effects between house prices of neighboring properties. Lesage and Pace (2009) give some interpretations of the spatial lag model, not all of which are consistent with the equilibrium assumption underlying the hedonic approach. In particular, such spillovers could describe the process of neighborhood gentrification in which wealthier households move in and in doing so change the composition of the neighborhood which leads to higher prices and so on. ${ }^{4}$ It seems unlikely that the hedonic price function should remain the same in a new equilibrium if the composition of a neighborhood changes. Alternatively, the spillover can be interpreted as an information effect. If sellers and buyers are unsure of the appropriate value of a property given its characteristics, they may infer the appropriate price from looking at nearby properties with similar characteristics which have been sold recently. The information contained in previous transactions in the same area may also allow the household to form expectations about the future evolution of the prices in the area. For each of these interpretations, however, it is clear, there should be a subscript $t$ indicating that the spillover effect occurs from recently sold properties to future sales and not vice versa. In most applications of the spatial lag model, that distinction is not made.

Gibbons and Overman (2012) emphasize the need to think of the theoretical context before specifying the model rather than choosing a model based on statistical tests. This becomes especially important as the spatial lag model implies the existence of a spatial multiplier on marginal effects which leads directly to higher marginal prices. Lesage and Pace (2009) distinguish between average direct, indirect and total impacts, depending on whether one looks solely at the estimated coefficient or accounts for neighboring observations. A similar interpretation is given in Won Kim et al. (2003), where the marginal price of a housing characteristic (total impact) becomes:

$$
\frac{\partial P}{\partial x}=\beta\left(I-\rho W_{p}\right)^{-1}
$$

When spatial correlation is positive and large, this multiplier can be quite significant. Small and Steimetz (2006) argue that the multiplier should only be applied when the spillover is technological, but not when it is purely informational. It is very hard empirically to distinguish between these interpretations as the model does not identify the source of the spillover. It seems unintuitive that the addition of e.g. an additional square meter of living area to a house should have value for all the neighbors. Nor does it seem intuitive

\footnotetext{
${ }^{3}$ A spline is a combination of a series of basis functions over covariate space. Basis functions can consist of e.g. polynomials of increasing order. A higher number of basis functions translates into more flexibility in the functional form.

4 "We need to keep in mind that the scalar summary measures of impact reflect how these changes would work through the simultaneous dependence system over time to culminate in a new steady state equilibrium." (LeSage \& Pace (2009), p. 37)
} 
that this value including spillovers should correspond to the individual household's willingness to pay for the improvement, which is essentially what the model implies in a hedonic context. Several alternatives are available to address spatial correlation, which are more in tune with the underlying hedonic model.

A reason for the common use of the spatial lag model is that model estimations are likely to find the autoregressive parameter to be significantly different from zero. This finding may just as well be due to omitted variable bias and in any case does not imply that the chosen model correctly captures the spatial processes, see also McMillen (2012). From equation 2.6, it is clear that the elements in $W y$ and $u$ will be correlated and an IV approach is used for consistent estimation, e.g. Kelejian and Prucha (2010). The instruments are constructed based on spatially lagged exogenous variables. For housing market applications the instruments would be a weighted combination of the characteristics of nearby properties. If prices are high in an area, the households living there tend to be wealthy, and the average wealth of a neighborhood will be correlated with crime rates, school quality and the neighborhoods general appearance as well as the size and style of a home. The lagged dependent variable is likely to be a proxy for these often unobserved characteristics. The instruments used to identify the spatial lag model may not be redundant in the model in the first place. In other words, estimating a significant spatial correlation coefficient does not imply that the model is a good approximation to the truth.

\subsection{Fixed effects}

Spatial fixed effects are quite popular as a control for omitted variables. Basically, fixed effect estimation corresponds to including a dummy variable for belonging to a geographical entity in the data. In that sense, fixed effects are similar to the use of spatial weight matrices with contiguity indicators, except the matrix is not centered on each observation but rather identifies observations belonging to the same spatial entities. With fixed effects, each observation belongs to only one neighborhood entity, whereas an observation can belong to several neighborhoods as these are defined by the weight matrix in the spatial econometric models. Remaining spatial correlation in the error term can be accounted for by clustering errors within entities to avoid overestimating significance levels. Fixed effects are easy to implement and can be more flexible than the parametric models in capturing the unknown urban structure depending on their level of aggregation. The flexibility comes at the cost of a loss of degrees of freedom when many fixed effects are included. Essentially, where the standard spatial econometric model estimates one or two spatial lag parameters, the fixed effect model estimates additional parameters corresponding to the number of entities in the data set. As data availability increases, sample sizes have also grown to make this constraint less binding.

Fixed effects imply discrete shifts in the level of house prices as one moves across the border of the entity used to establish the panel structure. The effect of omitted variables is constrained to be constant within the entity and only vary between entities. Just as the specification of the weight matrix determines the relevant neighborhood size, the fixed effect should coincide with the level at which the omitted variables vary in order to be effective. Unfortunately, the nature of most omitted processes is unobservable to the econometrician. In existing studies, fixed effects are usually created based on availability of, e.g. administrative units such as provinces in Brounen and Kok (2011), counties in Deaton and Vyn (2010) or municipalities as in Cavailhes et al. (2009), or they are created from the object of interest, i.e. beaches in Gopalakrishnan et al. (2011) or lakes in Walsh et al. (2011). The use of small entities is preferable to the use of larger ones with respect to controlling appropriately for omitted variable bias.

Fixed effects based on small entities demand a lot of variation in the data. There must be sufficient spatial or temporal variation in the data within the spatial entity to distinguish the variable of interest from 
the fixed effect. In the extreme case of a repeat sales model, only the effect of variables which change over time can be identified. In cross-sections, using census block or school district fixed effects can make it very difficult to recover impacts of amenities such as air pollution or airport noise, which vary little across space. Any effect they might have on housing prices is likely to be "sucked up" in the fixed effect. ${ }^{5}$ For proximity measures as well, the use of fixed effects can make estimation of parameters for such amenities as park access difficult. The variation in proximity to the nearest park within a spatial entity declines, the smaller the entity is. Proximity measures of spatially delineated amenities, which are scarce in the landscape, tend to vary less across observations than proximity to spatially delineated amenities found at several locations, which makes it more difficult to identify any effect they might have on housing prices.

\subsection{Generalized additive modeling: A "flexible" fixed effect}

Several non-parametric and semi-parametric approaches exist to account for spatially correlated data. All of these methods are based on the recognition that the researchers have limited knowledge of the spatial structure and processes of the market. Rather than impose structure on the data, the data is allowed to speak. One such alternative is the Locally Weighted Regression (LWR), see e.g. McMillen (2012). The LWR is characterized by locally estimating parameters leading to variation in parameters across space. This variation will reflect any omitted spatial processes in so far as they correlate locally with the variables included in the model. ${ }^{6}$ The generalized additive model discussed below allows variation in the overall level of prices across space through a flexible fixed effect, but keeps parameters constant. Essentially the model can be written as:

$$
P=g^{-1}\left(X, f_{1}\left(x_{l o n}, y_{l a t}\right) ; \beta\right)
$$

where $g^{-1}(\bullet)$ is the inverse of the link function, and $f\left(x_{l o n}, y_{l a t} ; k\right)$ is a smooth function of the spatial coordinates capturing the exact location of the property. The smooth function is made up of the sum of $k$ thin plate regression spline bases $b_{h}(\bullet)$ multiplied by their coefficients to be estimated: $f=\sum_{h=1}^{k} \beta_{h} b_{h}\left(x_{l o n}, y_{l a t}\right)$. The non-parametric component of the model $f\left(x_{l o n}, y_{l a t} ; k\right)$ is fitted using thin plate regression splines with a penalty on "wiggliness". The penalty, $\theta$, is determined from the data using generalized cross validation or related techniques. The penalty enters the objective function directly through an additional term capturing wiggliness in the smooth function, i.e.:

$$
\|P-\widehat{P}\|^{2}+\theta \iint\left[\frac{\partial^{2} f}{\partial x_{l o n}^{2}}+\frac{\partial^{2} f}{\partial x_{\text {lon }} \partial y_{\text {lat }}}+\frac{\partial^{2} f}{\partial y_{\text {lat }}^{2}}\right]^{2} d x_{\text {lon }} d y_{\text {lat }}
$$

Here $\widehat{P}$ is the fitted dependent variable and the second derivatives of the smooth function describe its wiggliness. The objective function explicitly contains the trade-off between bias and variance. ${ }^{7}$ The researcher must choose the flexibility of the model by setting the number of basis functions $k$. This is a balancing act between accurately capturing the locational attribute without overfitting the model, although the penalty term also reduces the probability of overfitting.

The higher the choice of $k$, the less spatial variation remains in the data to be explained by other

\footnotetext{
${ }^{5}$ Abbott and Klaiber (2010a) have shown in the context of green space, that a spatial Hausman-Taylor model can recover components which do not vary within fixed effect entities. However, that solution requires that good instruments are available for the variable of interest.

${ }^{6}$ Geniaux and Napoleone (2008) compare LWR with a Generalized Additive Model similar to the one discussed here.

${ }^{7}$ More information on the fitting of GAM with thin plate regression splines and the use of GCV and alternative methods can be found in, e.g. Wood (2006) and in the vignette for the mgcv package in R.
} 
variables. In this way, there is a clear parallel between the choice of $k$ and the scale of the spatial fixed effect. Essentially, it is difficult to separate the influence of included covariates from that of omitted processes when both vary on a spatial scale. We require the included spatial covariates to vary on a finer spatial scale than the omitted spatial processes in order to identify them in the model. In comparison with the fixed effects estimator discussed above, there will be no discrete changes in the level of house prices across space in the GAM model. The location component instead acts as a sort of "flexible" fixed effect describing the landscape. Sensitivity to the scale of the fixed effect can then be carried out easily by varying the choice of $k$ as we demonstrate below.

In the empirical example in this paper, the focus is on the flexible fixed effect, but it should be noted that the GAM has several other properties desirable for hedonic analysis. In addition to smoothing the spatial coordinates, the GAM can also include smooth terms for other regressors, e.g. to determine an appropriate functional form. Furthermore, the GAM is a semi-parametric version of a generalized linear model (GLM). As such it naturally incorporates log transformation of the dependent variable, which is common in hedonic analysis. For calculation of marginal prices, the predicted (expected) price in levels rather than logs must be calculated after estimation. With GLM and a log transformed dependent variable that calculation needs to take account of heteroscedastic errors using, e.g. Duan smearing, see Cameron and Trivedi (2009). For estimation of the GAM a logarithmic link function can be specified, and levels rather than logs can be predicted directly.

\section{Empirical application}

The purpose of the following empirical exercise is to illustrate the sensitivity of the results from hedonic modeling to different spatial specifications and modeling principles. To that end, we estimated the hedonic price function using four different models: a simple linear model with no spatial corrections, a SEM, a spatial fixed effect model and a GAM. For the SEM, we then vary the choice of weight matrix, and for the GAM, the number of basis functions to evaluate the sensitivity of our results to the level of the spatial correction.

In each of the models, we model spatial processes in the data in two ways: To capture the finer structure at a neighborhood level we include a vector of variables $Z_{i}$ which describes the average visible characteristics of homes in the neighborhood of dwelling $i$ at the level of the road for each house. These average characteristics are calculated based on all houses (including those not traded within our time frame) in the same street as house $i$, and are intended to proxy for unobservable neighborhood characteristics in close proximity to the individual dwelling. On a large spatial scale, our approach varies across the spatial models. For the parametric models we include a linear measure of the distance to the central business district. The fixed effect model additionally has fixed effects at the level of school districts. For the GAM our approach is based on the recognition that we do not know a priori how the land rent gradient declines as the distance from the center increases. For this reason, we model the location of the property through a smooth function of the spatial coordinates, rather than by including distance to the central business district. The smooth spatial component captures the shape of the land rent gradient. These approaches account for the spatial structure of the housing market at an aggregate level in our models.

To facilitate comparison across models, we have made a number of common assumptions: All models are estimated with maximum likelihood estimators and assume a Gaussian distribution. The choice of estimator is not perfect for either the SEM or the GAM. For the SEM, the GMM approach developed by Kelejian and Prucha (2010) would be a better option as it allows for unknown heteroskedasticity and is computationally fast. The GAM requires specification of an exponential family distribution for the dependent variable. As 
the house price is always positive and the variance increases with the price, a Gamma distribution would be a more appropriate choice than the Gaussian distribution applied here. For each of the models, the dependent variable was log-transformed before estimation.

We estimate the generalized additive model:

$$
\ln P_{i}=X_{i} \beta+Z_{i} \gamma+f\left(x_{l o n, i}, y_{l a t, i} ; k\right)+u_{i}
$$

where $f\left(x_{l o n}, y_{\text {lat }} ; k\right)$ is a smooth function of the spatial coordinates capturing the exact location of the property. The SEM is specified with a simple linear term to account for the distance from the Central Business District (CBD): ${ }^{8}$

$$
\begin{gathered}
\ln P_{i}=X_{i} \beta+C B D_{i} \delta+Z_{i} \gamma+u_{i} \\
u_{i}=\lambda W u_{i}+\eta_{i} \\
\eta_{i} \sim N\left(0, \sigma_{\eta}^{2}\right)
\end{gathered}
$$

For the error model we used a row standardized spatial weight matrix, $W$, which captures the 10 nearest neighbors. The chosen spatial weight matrix corresponds to the standard choice of spatial weight matrix in the literature. The linear model is identical to (3.2)-(3.4) with $\lambda=0$. Finally, the fixed effect specification is given by:

$$
\ln P_{i j}=a_{j}+X_{i} \beta+C B D_{i} \delta+Z_{i} \gamma+e_{i j}
$$

where $a_{j}$ is the fixed effect for school district $j$. For the fixed effect model, errors were clustered at the school district level to account for residual spatial correlation.

All models are estimated in R(2012). The non-spatial linear model and the fixed effect model are estimated using software for generalized linear models $(\mathrm{glm})$. The generalized additive model is estimated with the mgcv package developed for R by Simon Wood, see e.g. Wood and Augustin (2002), and the SEM is estimated using the spdep package (Bivand, 2012).

\subsection{Data}

The data set covers the transactions of single family houses in the city of Aalborg, Denmark, over the period from 2000 to 2007. The study area is depicted in figure 3.1 which shows the distribution of transacted properties on a map of the buildings in Aalborg. Aalborg is the fourth largest town in Denmark with approx. 125,000 inhabitants (2010). In terms of owner occupied dwellings approximately half of the available housing units consist of houses. In total 6,313 transactions were included in the analysis.

\footnotetext{
8 The specification we have chosen for the spatial processes in equations (3.2) to (3.3) is a spatial autoregressive model, which implies that the spatial variation occurs over a larger area than would be the case with, e.g. a spatial moving average representation where correlations die out faster as we move further away from the single observation. The neighborhood variables in $Z_{i}$ are intended to capture more local effects and were also included in our estimates of the SEM.
} 


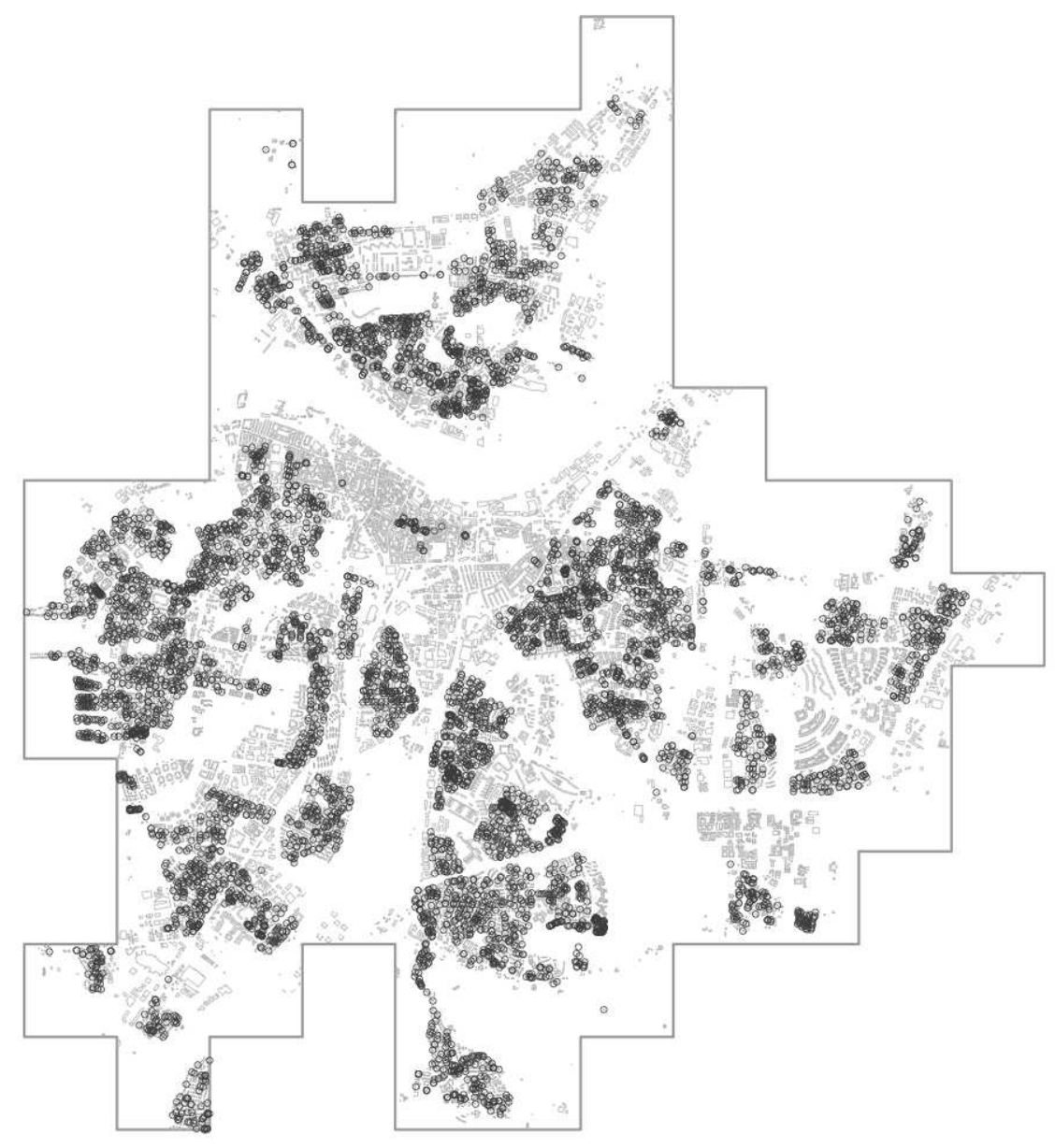

Fig. 3.1: The survey area, single family and terraced houses

The data set contains information about each transaction in terms of price, date and type of sale. Data also contains information on the structural characteristics of the property such as the number of rooms and size of the living area. A summary of the control variables in the data set is found in Table 1. The information was extracted from the Danish Registry of Buildings and Housing database which contains information on all dwellings in Denmark (Ministry of Housing, 2012). The data is a "snapshot" of the housing characteristics and is continuously updated. Our data therefore reflects the characteristics of a house in August 2011 when the data were collected. The register contains information on the date of the latest renovation, so it is possible to control for post-sale renovations. The exact coordinates of the location of each dwelling are also available. Based on this information and maps from the Danish National Survey and Cadastre, a number of measures of proximity have been calculated using ArcGIS desktop 10.1, e.g. proximity to large roads, industrial sites, and different types of green space. 
Tab. 1: Control variables describing housing characteristics

\begin{tabular}{|c|c|c|}
\hline Structural variables & Spatial Variables & Neighborhood variables $(Z)$ \\
\hline Size of living area & Highway & Average Garden \\
Room & Large Road & Share with Brick walls \\
Garden area & Railway track & Average Age \\
Basement & Industrial area & Share with Tile roof \\
Number of floors & Coastline & Share Renovated in 1970s \\
Number of apartments & City Center & Share Renovated in 1990s \\
Low basement & Park & Share Renovated in 2000s \\
Renovation 1970s & Nature & \\
Renovation 1980s & Lake & \\
Renovation $1990 \mathrm{~s}$ & Common area & \\
Renovation 2000s & Sport field & \\
Built before 1927 & Agriculture field & \\
Built between 1927 and 1939 & Scrapland & \\
Built between 1939 and 1955 & Churchyard & \\
Built between 1955 and 1975 & Other locational & \\
Built between 1975 and 1999 & Hasseris (High income area) & \\
Brick walls & Geographical coordinates & \\
Tile roof & & \\
Fiber board roof & & \\
\hline
\end{tabular}

The neighborhood variables contained in our vector Z (see Equation 3.1, 3.2, 3.5) hold information about the appearance of surrounding properties in terms of the average age, average of dummies for renovation in the years preceding the sale, and the style of the building as captured by roof type and brick walls. Finally, the average size of gardens for houses in the same street was included as this gives an idea of the development density in the area. A description and a set of descriptive statistics of the data are found in appendix A. Given that the data set comprised 8 years of sales it was necessary to adjust for inflation in the house prices. We did this by fitting a fourth degree polynomial in the date of sale. In this way the inflationary movements are filtered out leaving the remainder of the variation in house prices to be explained by the housing characteristics in the model.

As we have several control variables describing each house, we limit our discussion of results to a few variables. Access to green space is inherently a spatial variable and has long been a topic for hedonic analysis. Recent surveys include McConnell and Walls (2005) and Waltert and Schlaepfer (2010). As green space has been so extensively studied (and such variation in results has been found) it is a useful example for our purposes, namely to demonstrate sensitivity to spatial modeling choices. We have identified several different types of green space which differ both in the services provided and in terms of their prevalence in the urban landscape. Our discussion of results will mainly focus on parks, natural areas, residential common areas, lakes, and scraplands for brevity. We also discuss the robustness of a few of the so-called "structural" characteristics of the houses for comparison. These variables are the size of the living area, lot size, and type of wall covering. Variation in these characteristics is not primarily spatial, and parameter estimates should therefore be less sensitive to the choice of spatial model for these variables.

\subsection{Modeling spatial variables}

The spatially delineated variables in the hedonic price function proxy for accessibility or exposure to an amenity. In general, the effect of such amenities have a limited spatial extent. Apart from air pollution 
the majority of the hedonic literature has focused on amenities with a local impact (Palmquist, 2005). The spatial extent of the amenity should be given careful consideration. If no boundary is specified for the effect of the amenity in question, these proximity measures may end up capturing possible omitted spatial trends in the data, which are unconnected with the amenity. We therefore specify cut-off distances for these spatial variables beyond which the effect of the amenity is expected to be absent.

We describe accessibility to green space using proximity to the nearest property in a straight line with the exception of the common area category. Common area green space is attached to specific residential areas, which means that distance to nearest common area is generally small. However, the size of common areas varies and is included as our regressor. We work with two different proximity cut-offs $\left(c_{\text {cutoff }}\right)$ for different types of green space to capture different scales of capitalization (Abbott and Klaiber, 2010b). Some types of public green space are used for outings and people would be willing to travel further to enjoy a stay in such a green space, whereas other types of green space are de facto a club good, e.g. because they are small and located out of the way in the middle of a residential area. This should be reflected by capitalization of the latter types at a more local scale. We set the high cut-off to 600 meters reflecting an 8-10 minute walking time for parks and natural areas. The lower cut-off for club goods was set at 300 meters for the remaining types of green space. The scale of proximity is calculated by $X_{\text {prox }}=c_{\text {cutoff }}-X_{\text {dist }}$, where $X_{\text {dist }}$ is distance in a straight line from the house. Further, for homes beyond the cut-off distance the measure of amenity access is set to zero, $\left\{X_{\text {prox }} \mid X_{\text {prox }}<0\right\}=0$. The coefficients on the proximity variables are easy to interpret as amenities are expected to have positive coefficients and disamenities to have negative coefficient estimates. A quadratic specification has been applied to all green space proximity variables, as previous studies have found non-constant marginal effects (Panduro and Veie, 2013). The common space variable has not been transformed.

Tab. 2: Descriptive statistics - selected regressors

\begin{tabular}{|c|l|c|c|c|c|}
\hline & spec & count & Min & Median & Mean \\
\hline Parks & Prox. (meters) & 18 & 3.7 & 943.8 & $1,277.1$ \\
Natural areas & Prox. (meters) & 60 & 0 & 486.8 & 562.8 \\
Lake & Prox. (meters) & 6 & 0 & $1,739.6$ & $1,779.6$ \\
Common area & Size (Ha) & 113 & 0.2 & 0.7 & 1.5 \\
Scraplands & Prox. (meters) & 269 & 2.4 & 366.9 & 420.5 \\
Size (log) & Size (log) $\left(m^{2}\right)$ & - & 4.0 & 4.9 & 4.9 \\
Garden & Size $\left(m^{2}\right)$ & - & 0 & 736 & 681 \\
Brick & Dummy & 6,016 & - & - & - \\
\hline
\end{tabular}

\section{Results}

\subsection{Model estimates}

Table 3 includes estimates for the GLM model, the fixed effect model, the SEM, and the GAM. The table contains parameter estimates of the selected regressors from table 2. The performance of each model is described by $R^{2}$, log likelihood, and AIC. Spatial autocorrelation of the residuals of each of the models are tested using a global Moran's I statistic based on a row standardized inverse distance weighted spatial weight matrix with a cut-off value of 500 meters. On average a 500 meters distance corresponds to 130 neighbors in the weight matrix, however, the number of neighbors varies with the density of the urban area. Parameter estimates of the full models can be found in appendix B. 
The estimates of the structural variables across all four models are highly significant and vary only marginally. Among the spatial variables, proximity to parks, scraplands and the size of the nearest common area are associated with significantly higher and lower prices. Proximity to natural areas does not have a significant impact on the house price in the fixed effect model. For the GLM and the SEM an effect is significant at a 5 and $10 \%$ level, respectively. The GAM provides highly significant estimates of the effect of proximity to natural areas, and proximity to lakes at the $10 \% \mathrm{t}$ level, but it should be noted, that the standard errors for the GAM and the GLM do not take account of the clustering of residuals in space. Hence significance levels for these two models are likely to be overestimated. The estimated coefficients for the spatial variables have the expected signs for all models except for the Common area variable, which has a negative effect. There is some variation in the size of the estimated coefficients. For proximity to Scraplands, the largest estimate (GAM) is 1.4 times as large as the smallest (SEM), although the value lies within the spatial error confidence interval. Looking across models, the span of coefficient estimates is rather wide and it is not without importance which model is used to calculate marginal prices.

The Moran's I statistic shows that the residuals of the models are significantly clustered in space within 500 meters of each dwelling. Although the Moran's I values for the residuals are significant for all models, they are relatively small, which may be due to the number of spatial covariates in the model. The GAM has the lowest Moran's I value followed by the SEM, the fixed effect model, and the GLM model. The GAM's focus on spatial processes at a broader level may explain why it performs better than the SEM with 10 neighbors in the weight matrix for the displayed Moran's I statistic.

In the SEM, the spatial autocorrelation coefficient, $\lambda$, is highly significant. The spatial smooth term in the GAM is highly significant and can be understood as the land rent gradient of the housing market. The spatial smooth term is mapped below in figure 4.1.

While the three spatial models cannot be compared directly as they are not nested, the fixed effect model and the error model are directly comparable to the GLM model and perform better on all the displayed model criteria in table 3. In the GAM, the proximity to the central business district has been replaced with the smooth "land rent gradient", which seems to increase the model's performance significantly, although, the loss of degrees of freedom is also larger than for the other spatial models. 
Tab. 3: Model estimates

\begin{tabular}{|c|c|c|c|c|c|c|c|c|}
\hline & \multicolumn{2}{|l|}{ GLM } & \multicolumn{2}{|c|}{ Fixed effect } & \multicolumn{2}{|l|}{ SEM } & \multicolumn{2}{|l|}{ GAM } \\
\hline \multicolumn{9}{|c|}{ Spatial variables } \\
\hline Park $^{2}$ & $\begin{array}{r}0.001831 \\
(0.000458)\end{array}$ & $* * *$ & $\begin{array}{r}0.003257 \\
(0.000745)\end{array}$ & $* * *$ & $\begin{array}{r}0.001881 \\
(0.000737)\end{array}$ & $*$ & $\begin{array}{r}0.002296 \\
(0.000561)\end{array}$ & $* * *$ \\
\hline Nature $^{2}$ & 0.000739 & $*$ & 0.000232 & & 0.000994 & + & 0.001474 & $* * *$ \\
\hline & $(0.000339)$ & & $(0.000907)$ & & $(0.000527)$ & & $(0.000441)$ & \\
\hline Lake $^{2}$ & 0.000132 & & 0.000992 & & 0.000539 & & 0.001467 & + \\
\hline & $(0.000496)$ & & $(0.001012)$ & & $(0.000807)$ & & $(0.000762)$ & \\
\hline Scrapland $^{2}$ & -0.006646 & $* * *$ & -0.006308 & $* *$ & -0.005306 & * & -0.007624 & $* * *$ \\
\hline & $(0.001703)$ & & $(0.002239)$ & & $(0.002466)$ & & $(0.001867)$ & \\
\hline \multirow[t]{2}{*}{ Common area } & -0.004235 & $* *$ & -0.0048543 & + & -0.003597 & * & -0.002167 & + \\
\hline & $(0.001436)$ & & $(0.002598)$ & & $(0.001442)$ & & $(0.001237)$ & \\
\hline \multicolumn{9}{|c|}{ Structural variables } \\
\hline \multicolumn{9}{|c|}{$0.490631 \quad * * *$} \\
\hline & $(0.018421)$ & & $(0.02892)$ & & $(0.016441)$ & & $(0.016404)$ & \\
\hline \multirow[t]{2}{*}{ Garden } & 0.000177 & $* * *$ & 0.000176 & $* * *$ & 0.000190 & $* * *$ & 0.000176 & $* * *$ \\
\hline & $(0.000017)$ & & $(0.000026)$ & & $(0.000013)$ & & $(0.000012)$ & \\
\hline \multirow[t]{2}{*}{ Brick } & 0.078805 & $* * *$ & 0.078454 & $* * *$ & 0.081458 & $* * *$ & 0.080204 & $* * *$ \\
\hline & $(0.013950)$ & & $(0.01397)$ & & $(0.013908)$ & & $(0.013834)$ & \\
\hline & & & & & 0.49081 & $* * *$ & & \\
\hline$k_{g e o}$ & & & & & & & 40 & $* * *$ \\
\hline & & & & & & & t-statistic: 23.66 & \\
\hline & & & & & & & 38.584 edf. & \\
\hline GCV-score & & & & & & & 0.043363 & \\
\hline df. & 45 & & 66 & & 46 & & 82 & \\
\hline$R^{2}(A d j)$. & 0.6838 & & 0.6909 & & 0.7154 & & 0.706 & \\
\hline Log likelihood & 784.5938 & & 868.9638 & & 1038.626 & & 1029.708 & \\
\hline $\mathrm{AIC}$ & -1479.2 & & -1605.928 & & -1985.3 & & -1894.722 & \\
\hline Moran's I & 0.110042 & $* * *$ & 0.08974707 & $* * *$ & $0.05307406^{* * *}$ & & 0.02356792 & $* * *$ \\
\hline
\end{tabular}

Note: $* * *: p<0.001, * *: p<0.01, *: p<0.05,{ }^{+}: p<0.1$

\subsection{Spatial smoothing}

According to Wood (2006) the choice of basis dimensions is a part of model specification and the researcher should aim to ensure that sufficient flexibility is available for the individual application. The results presented in table 3 are for a basis dimension of $k=40$ for the geographical coordinates, which was chosen based on a rule of thumb: $k=\min \left\{\frac{n}{4}, 40\right\}$, see Ruppert (2002). The penalty term, $\theta$, was determined through generalized cross-validation. The estimated spatial structure is depicted in the contour plots in figure 4.1. The plots show the spatial pattern of the log of the transactions price at the median of the covariates for properties built in the period between 1955 and 1975.

Generally speaking, the spatial price trend in Aalborg seems to conform to a wave of high prices rising in the southern part of Aalborg and falling near the industrial area near the harbor area. A local depression in prices is found northeast of the city. Note that the rate of decline in prices depends on the direction of movement away from the high price areas. 
Fig. 4.1: Spatial Smoothing

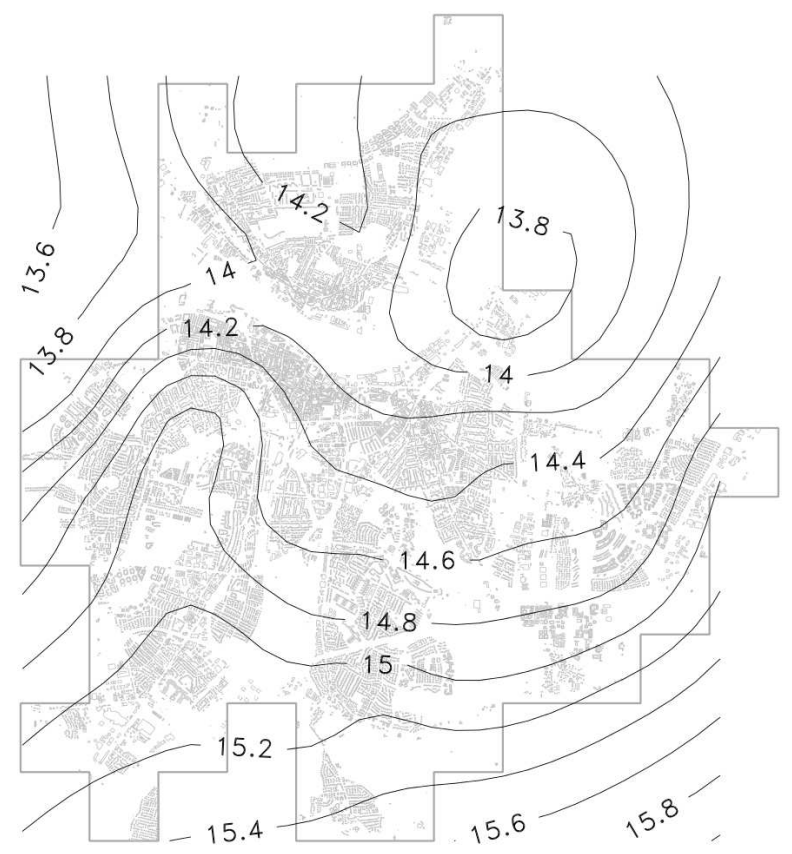

\subsection{Sensitivity analysis - spatial autocorrelation}

Our models capture spatial processes at different levels with the SEM being the most localized and the GAM capturing broader trends in the data. As the spatial processes in the data are likely to occur at varying spatial frequencies, we test spatial autocorrelation for each of the four models within 9 distance bands. The nearest ring spans 0-200 meters around the observation, the next ring spans to 200-400 meters and so forth all the way up to 2500-3000 meters, see table 4. The tests are based on global Moran's I values for the residuals from each model against the null hypothesis of spatially random errors. Each of the distance bands is represented by a row standardized spatial weight matrix which assumes equal weights on the observations within the distance bands.

The global Moran's I values for the GLM model are significantly different from a random distribution across all distances bands. The Moran's I values decline rapidly from the nearest distance band at 0-200 meters. The residuals of the GLM model are significantly more clustered at all distance bands up to 800-1000 meters. Beyond this distance band, the residuals are significantly more dispersed than expected (negative Moran's I) if their distribution was random across space. The Moran's I values of the fixed effect model are generally lower than for the GLM model and only positive until the 800 meter band, after which they become negative. Both for the GAM and the SEM, Moran's I is lower than the GLM model at almost all distance bands. The SEM has fewer significant Moran's I values than the GAM. The GAM seems to result in overdispersed residuals at shorter distances than the other models.

To test sensitivity of the SEM and the GAM to the choice of weight matrix and basis function dimension, we varied these choices, re-estimated the models and re-calculated Moran's I for the different distance bands. 
The SEM is re-estimated using a row standardized spatial weight matrix based on the 10,20,30, 40 and 50 nearest neighbors and then tested across the spatial distance bands (see table 5). For the SEM, residuals remain significantly clustered in those distance bands closest to the house as we increase the number of neighbors in the weight matrix. Spatial autocorrelation is reduced with an increase of neighbors in the error model based on 30, 40 and 50 nearest neighbors although significant global Moran's I values remain. The choice of 30 neighbors seems significantly better than 10 neighbors based on the calculated statistics. The GAM is re-estimated using a basis dimension of $k=\{20,40,60,80,100\}$ for the spatial smoothing splines (see table 6). The presence of spatial autocorrelation is reduced with an increase in the number of basis dimension especially for distance bands further away from the dwelling. However even for $k=100$, significant clustering remains at a local level although the Moran's I values are small.

None of the spatial models completely removes the presence of spatial autocorrelation in the residuals, although there is less of a spatial pattern in the residuals as the spatial dimension is increased. There is no monotonic decline in the Moran's I values as we increase the dimension of the weight matrix or increase the choice of basis functions. Increasing the weight matrix corresponds to using a larger window in kernel estimation. Hence it is unsurprising that Moran's I for the nearest distance band should increase as the number of neighbors gets large. With a larger window size, the finer spatial processes will not be captured as precisely. Naturally, the results may differ if the spatial weights decline with distance, i.e. inverse distance weighting. For the GAM, different choices of $k$ also seem to capture different spatial processes as the Moran's I statistic becomes insignificant for varying distance bands. In both cases, the findings are consistent with the existence of several distinct spatial processes. Note that variations in weight matrix and basis spline dimension in the GAM model and the SEM are not directly comparable. We have no way of determining what a given number of smoothing splines corresponds to in terms of spatial weight matrix.

Tab. 4: Moran's I for different distance bands

\begin{tabular}{rcccc}
\hline Distance band & GLM & Fixed effects & \multicolumn{1}{c}{ SEM $^{a}$} & $\mathrm{GAM}^{a}$ \\
\hline $0-200$ & $0.1234^{* * *}$ & $0.1032^{* * *}$ & $0.0197^{* * *}$ & $0.0660^{* * *}$ \\
$200-400$ & $0.0597^{* * *}$ & $0.0373^{* * *}$ & $0.0230^{* * *}$ & 0.0049 \\
$400-600$ & $0.0338^{* * *}$ & $0.0158^{* * *}$ & $0.0133^{* * *}$ & $-0.0113^{* * *}$ \\
$600-800$ & $0.0252^{* * *}$ & $0.0066^{* *}$ & $0.0121^{* * *}$ & $-0.0098^{* * *}$ \\
$800-1000$ & $0.0100^{* * *}$ & $-0.0055^{*}$ & 0.0037 & $-0.0095^{* * *}$ \\
$1000-1500$ & $-0.0054^{* * *}$ & $-0.0116^{* * *}$ & -0.0018 & $-0.0082^{* * *}$ \\
$1500-2000$ & $-0.0036^{* *}$ & $-0.0028^{* *}$ & -0.0014 & $0.0062^{* * *}$ \\
$2000-2500$ & $-0.0093^{* * *}$ & $-0.0022^{*}$ & $-0.0041^{* * *}$ & $0.0024^{* *}$ \\
$2500-3000$ & $-0.0111^{* * *}$ & -0.0008 & $-0.0046^{* * *}$ & $-0.0018^{*}$ \\
\hline
\end{tabular}

Note: ***: $p<0.001,{ }^{* *}: p<0.01,{ }^{*}: p<0.05,{ }^{+}: p<0.1$

a) The SEM estimated with 10 neighbors and the GAM estimated with $k=40$. 
Tab. 5: Spatial autocorrelation - SEM

\begin{tabular}{rllllc}
\hline Dist. $\backslash$ Neigh. & \multicolumn{1}{c}{10} & \multicolumn{1}{c}{20} & \multicolumn{1}{c}{30} & \multicolumn{1}{c}{40} & 50 \\
\hline $0-200$ & $0.0197^{* * *}$ & $0.0094^{* *}$ & $0.0094^{* *}$ & $0.0146^{* * *}$ & $0.0232^{* * *}$ \\
$200-400$ & $0.0230^{* * *}$ & $0.0123^{* * *}$ & 0.0050 & -0.0010 & -0.0038 \\
$400-600$ & $0.0133^{* * *}$ & $0.0073^{* *}$ & 0.0051 & 0.0032 & 0.0023 \\
$600-800$ & $0.0121^{* * *}$ & $0.0077^{* *}$ & $0.0059^{*}$ & $0.0052^{*}$ & 0.0044 \\
$800-1000$ & 0.0037 & 0.0022 & 0.0023 & 0.0021 & 0.0028 \\
$1000-1500$ & -0.0018 & -0.0014 & -0.0009 & -0.0002 & 0.0002 \\
$1500-2000$ & -0.0014 & -0.0000 & 0.0010 & 0.0015 & 0.0014 \\
$2000-2500$ & $-0.0041^{* * *}$ & $-0.0023^{*}$ & -0.0015 & -0.0013 & -0.0011 \\
$2500-3000$ & $-0.0046^{* * *}$ & $-0.0032^{* * *}$ & $-0.0030^{* * *}$ & $-0.0022^{* *}$ & $-0.0021^{*}$ \\
\hline
\end{tabular}

Note: ***: $p<0.001,{ }^{* *}: p<0.01,{ }^{*}: p<0.05,{ }^{+}: p<0.1$

Tab. 6: Spatial autocorrelation - Generalized additive model

\begin{tabular}{rccccc}
\hline Dist. $\backslash \mathrm{k}$ & \multicolumn{1}{c}{20} & \multicolumn{1}{c}{40} & 60 & 80 & 100 \\
\hline $0-200$ & $0.0820^{* * *}$ & $0.0660^{* * *}$ & $0.0453^{* * *}$ & $0.0365^{* * *}$ & $0.0310^{* * *}$ \\
$200-400$ & $0.0197^{* * *}$ & 0.0049 & $-0.0116^{* * *}$ & $-0.0185^{* * *}$ & $-0.0208^{* * *}$ \\
$400-600$ & -0.0000 & $-0.0113^{* * *}$ & $-0.0172^{* * *}$ & $-0.0181^{* * *}$ & $-0.0166^{* * *}$ \\
$600-800$ & $-0.0084^{* * *}$ & $-0.0098^{* * *}$ & $-0.0057^{*}$ & -0.0042 & -0.0023 \\
$800-1000$ & $-0.0115^{* * *}$ & $-0.0095^{* * *}$ & -0.0009 & 0.0023 & 0.0030 \\
$1000-1500$ & $-0.0097^{* * *}$ & $-0.0082^{* * *}$ & -0.0012 & 0.0005 & 0.0006 \\
$1500-2000$ & $0.0033^{* * *}$ & $0.0062^{* * *}$ & $0.0033^{* * *}$ & 0.0010 & 0.0010 \\
$2000-2500$ & -0.0006 & $0.0024^{* *}$ & 0.0001 & 0.0000 & -0.0000 \\
$2500-3000$ & $0.0015^{*}$ & $-0.0018^{*}$ & -0.0011 & 0.0000 & 0.0004 \\
\hline
\end{tabular}

Note: ***: $p<0.001,{ }^{* *}: p<0.01,{ }^{*}: p<0.05,{ }^{+}: p<0.1$

\subsection{Sensitivity analysis - coefficient robustness}

By increasing the dimension of the weight matrix in the SEM or the basis functions for the smooth component in the GAM we were able to remove much of the residual spatial autocorrelation. The next question is whether the estimated coefficients are robust to variations in the spatial dimension within models. The coefficient estimates for the selected regressors from table 2 are displayed in tables 7 and 8 for varying dimensions of the spatial weight matrix and geographical smoothing splines. The estimated parameters for structural (non-spatial) characteristics are robust across the spatial dimensions while the results for the spatially varying regressors are sensitive to the dimension of the spatial weight matrix in the error model and the number of spline basis functions. In the error model, parameter estimates for proximity to parks remain relatively stable and retain significance levels. For proximity to scraplands, the estimated parameter becomes larger in absolute terms as the number of neighbors increases. The significance level also increases. In the GAM, proximity to parks, natural areas and scraplands are significant up to 60 basis functions for the smooth land rent gradient. For larger $k$, the parameter estimates of parks become insignificant while nature and scrapland remain significant. The parameter estimates in the GAM for lake and common area are not robust. The lake variable is only significant at the 10 percent level for $k=40$ and $k=60$ and the size of the nearest common area is only associated with significantly different house prices with low values of $k$.

Scrapland is the only spatial variable which remains robust over both the different sizes of spatial weight matrices and varying levels of $k$ basis functions. As mentioned, the models differ in the assumptions about 
the correlations in the data. The error model assumes zero correlation between omitted spatial processes and included regressors, while the GAM captures the variation directly, as in the case of the fixed effects model. Of the two models then, the GAM seems the more prudent choice. This does not imply that access to, e.g. parks has no positive effect on house prices, it simply implies that these effects are hard to distinguish from omitted spatial processes using a high level of smoothing splines. Essentially, the smoothing splines compete with the spatial variables in explaining variations in the price levels across space. The variation in the variable of interest must be greater than the variation in the modeled spatial processes for an effect to be identified when the "flexible" fixed effect is included. In our case, the access to the (dis)amenity of interest is measured by proximity to the nearest object. For objects which are scarce in the urban landscape, there will be little variation in this measure across space. There are only 13 parks in the Aalborg area, whereas there are more than 200 scraplands spread out across the urban landscape.

Tab. 7: Spatial robustness - SEM

\begin{tabular}{r|rrrrrrrrrr}
\hline & 10 & & 20 & & 30 & & 40 & & 50 \\
\hline Park $^{2}$ & 0.001881 & $*$ & 0.001820 & $*$ & 0.002017 & $*$ & 0.002009 & $*$ & 0.001923 & $*$ \\
Nature $^{2}$ & 0.000994 & + & 0.001028 & + & 0.000980 & & 0.001207 & $*$ & 0.001395 & $*$ \\
Lake $^{2}$ & 0.000539 & & 0.000341 & & 0.000150 & & 0.000326 & & 0.000316 & \\
Scrapland $^{2}$ & -0.005306 & $*$ & -0.004996 & $*$ & -0.005829 & $*$ & -0.006688 & $* *$ & -0.007285 & $* * *$ \\
Common area & -0.003597 & $*$ & -0.002290 & & -0.000798 & & -0.000566 & -0.000489 & \\
Size (log) & 0.470979 & $* * *$ & 0.463614 & $* * *$ & 0.464899 & $* * *$ & 0.465234 & $* * *$ & 0.470670 & $* * *$ \\
Garden & 0.000190 & $* * *$ & 0.000187 & $* * *$ & 0.000183 & $* * *$ & 0.000180 & $* * *$ & 0.000175 & $* * *$ \\
Brick & 0.081458 & $* * *$ & 0.078656 & $* * *$ & 0.082338 & $* * *$ & 0.081681 & $* * *$ & 0.079803 & $* * *$ \\
\hline
\end{tabular}

Note: ***: $p<0.001,{ }^{* *}: p<0.01,{ }^{*}: p<0.05,{ }^{+}: p<0.1$

Tab. 8: Spatial robustness - generalized additive model

\begin{tabular}{|c|c|c|c|c|c|c|c|c|c|c|}
\hline & 20 & & 40 & & 60 & & 80 & & 100 & \\
\hline Park $^{2}$ & 0.001713 & $* * *$ & 0.002296 & $* * *$ & 0.001327 & $*$ & 0.000461 & & 0.000894 & \\
\hline Nature $^{2}$ & 0.001153 & $* * *$ & 0.001474 & $* * *$ & 0.001473 & $* *$ & 0.001949 & $* * *$ & 0.001612 & $* *$ \\
\hline Lake $^{2}$ & 0.000007 & & 0.001467 & + & 0.001587 & + & 0.001634 & & 0.001701 & \\
\hline Scrapland ${ }^{2}$ & -0.005905 & $* * *$ & -0.007624 & $* * *$ & -0.008231 & $* * *$ & -0.007963 & $* * * *$ & -0.006948 & $* * *$ \\
\hline Common area & -0.002919 & * & -0.002167 & + & -0.000612 & & -0.000312 & & -0.000808 & \\
\hline Size (log) & 0.494049 & $* * *$ & 0.490631 & $* * *$ & 0.484113 & $* * *$ & 0.485431 & $* * *$ & 0.482514 & $* * *$ \\
\hline Garden & 0.000178 & $* * *$ & 0.000176 & $* * *$ & 0.000171 & $* * *$ & 0.000170 & $* * *$ & 0.000171 & $* * *$ \\
\hline Brick & 0.081635 & $* * *$ & 0.080204 & $* * *$ & 0.077359 & $* * *$ & 0.075998 & $* * *$ & 0.076575 & $* * *$ \\
\hline
\end{tabular}

Note: $* * *: p<0.001,{ }^{* *}: p<0.01,{ }^{*}: p<0.05,{ }^{+}: p<0.1$

\section{Concluding discussion}

This paper builds on a criticism of the existing spatial (parametric) models, where the spatial structure is specified and treated as "known" either in terms of spatial weight matrices or through the use of spatial fixed effects. In practice, the spatial structure of omitted spatial processes is rarely known. We utilize an approach to account for spatial dependence which to our knowledge is novel to the literature on hedonic regressions. We model location as a semi-parametric function of the geographic coordinates which allows us to capture a large part of the spatial variation in the data using a GAM. We compare this model with alternatives commonly used in the literature: The SEM and the fixed effects model. We find the GAM to be 
a sound alternative to the standard approaches in the hedonic house price literature, having less restrictive assumptions about the omitted spatial processes while still being able to reduce the problem of spatial autocorrelation and provide trustworthy estimates of spatial variables.

Spatial correlation in the error term can result from misspecification of the functional form or mismeasurement of spatial covariates or from omitted spatial covariates. The most obvious property of these omitted spatial processes is that the researcher does not know at which scale misspecification, mismeasurement and omitted variables operate. We suggest, therefore, that sensitivity analysis should be conducted using different levels of spatial corrections to determine which results are robust across models. In the existing literature, when parametric spatial econometrics is used, it is rarely the case that results are shown for different choices of weight matrices. The standard approaches rely on the researcher to specify how the omitted spatial processes vary in order to control for them in the model. Our findings suggest that omitted spatial processes are likely to play an important role in explaining the varying findings in hedonic models concerned with spatially delineated amenities.

It is a rather restrictive assumption that spatial autocorrelation can be corrected by a single spatial entity as in the fixed effect model. Omitted spatial processes are likely to be present on more than one spatial scale, which implies that the fixed effect model should use as small entities as possible to ensure that omitted spatial processes are accurately captured. Ideally a repeat sales model is capable of doing this, but requires time series variation in the amenity of interest. The critique of restrictive assumptions about the nature of omitted spatial processes can also be applied to the SEM. The spatial weight matrix typically applied in the SEM defines the spatial pattern of the omitted processes and imposes this restriction on the estimation. Given that spatial autocorrelation is limited to unfold in the (x,y)-geographical space, the spatial weight matrix is bound to pick up some of the spatial autocorrelation even though the weight matrix incorrectly models the omitted spatial processes. The appropriate dimension of the spatial weight matrix is bound to differ from application to application and should always be carefully tested, e.g. using distance bands as in our example. The GAM applies less restrictive assumptions about the structure of the spatial pattern of the omitted spatial processes. Essentially, the GAM is data driven in the sense that the specification of the spatial omitted spatial processes is determined by model fit using generalized cross validation. The choice of basis function dimension for the GAM remains a judgment call for the researcher, however, and sensitivity analysis should be carried out to check robustness of the model estimates.

In the empirical application of the hedonic house price model we estimated a GLM model, a spatial fixed effect model, a SEM, and a GAM. The structural variables that describe the properties are robust across model specifications. Variation in the dimension of spatial processes modeled in terms of spatial weight matrices in the error model and spatial smoothing splines in the GAM also seems to leave the structural variables unaffected. The spatial variables, represented by different types of green space, are more sensitive to the choice of model and dimension of the spatial model. This is not surprising given that the controls for omitted spatial processes will to some extent compete with the spatial covariates in explaining the data. In the empirical application this is most obvious in the fixed effect model where the parameter estimate of proximity to natural areas becomes insignificant. For identification there must be sufficient variation in the variable of interest independent of the variation in omitted spatial processes which the models attempt to correct for. In practice it is often difficult to say if the variable of interest varies on a sufficiently fine scale. In the empirical application, proximity to natural areas might not vary sufficiently across space to be identified in the model independently of the fixed effect. The same problem occurs for other spatial variables in the fixed effect model and the GAM as the spatial dimension is increased (see appendix B). 
The SEM is able to reduce spatial autocorrelation better than the GAM at close distances. This does not apply at larger distances where the GAM outperforms the error model. The fixed effect model is not able to reduce spatial autocorrelation to the same extent as the two other spatial models. This is likely due to the relatively coarse scale of the fixed effect we employ. All three models do reduce residual spatial correlation in comparison with the linear model without spatial corrections. The error model assumes zero correlation between omitted spatial processes and included regressors. While zero correlation seems an appropriate assumption for non-spatial variables and a spatially correlated error term, it is less appropriate for the spatially varying regressors. We did not include a spatial econometric model with a spatial lag term in the empirical example. The interpretation of the spatial spillover in prices implied is hard to reconcile with Rosen's hedonic theory. Compared with the standard spatial econometric approaches the GAM model seems a prudent choice given its intuitive interpretation, the less restrictive assumptions and its ability to reduce the spatial correlation in the error term.

Although the potential for omitted variables bias is reduced through the increased use of geographical information systems to generate data, the inclusion of geographical covariates does not solve the omitted variable problem. Rather when spatially varying covariates are the main focal point of the analysis, extra care should be taken to ensure that results are robust to different spatial models as long as the true data generating process is unknown. In some cases spatial variation in the environmental variable in question can be increased through careful modeling of the services or sources of annoyance. For instance, in the empirical application we model accessibility by a proximity measure with a cut-off value which reflects the maximum distance that people are willing to travel in order to enjoy the amenity. We additionally construct neighborhood variables using the residential street to delineate the neighborhood. Despite these efforts spatial autocorrelation in the error term remains a problem. Careful attention to the nature of the environmental amenity and the way in which it is perceived by households improves the model's ability to measure household willingness to pay through reduction of measurement errors. However, for some environmental amenities cross-sectional hedonic analysis is unlikely to deliver reliable identification. Other methods are needed, such as instrumental variables with exogenous shifts in amenity levels, see Bayer et al. (2009), or quasi-experiments, see e.g. Pope (2008), though the latter are hard to interpret in terms of willingness to pay, see Kuminoff and Pope (2009). 


\section{References}

Abbott, J. K. and Klaiber, H. A.: 2010a, An embarrassment of riches: Confronting omitted variable bias and multi-scale capitalization in hedonic price models, Review of Economics and Statistics 93(4), 1331-1342.

Abbott, J. K. and Klaiber, H. A.: 2010b, Is all space created equal? uncovering the relationship between competing land uses in subdivisions, Ecological Economics 70(2), 296 - 307.

Anselin, L.: 2010, Thirty years of spatial econometrics, Papers in Regional Science 89(1), 3-25.

Anselin, L. and Lozano-Gracia, N.: 2008, Errors in variables and spatial effects in hedonic house price models of ambient air quality, Empirical Economics 34(1), 5-34.

Bayer, P., Keohane, N. and Timmins, C.: 2009, Migration and hedonic valuation: The case of air quality, Journal of Environmental Economics and Management 58(1), 1-14.

Bivand, R.: 2012, Spatial dependence: weighting schemes, statistics and models. R package version 0.4-56.

URL: http://cran.r-project.org/web/packages/spdep/index.html

Brady, M. and Irwin, E.: 2011, Accounting for spatial effects in economic models of land use: Recent developments and challenges ahead, Environmental $\&$ Resource Economics 48(3), 487-509.

Brounen, D. and Kok, N.: 2011, On the economics of energy labels in the housing market, Journal of Environmental Economics and Management 62(2), 166 - 179.

Cameron, A. C. and Trivedi, P. K.: 2009, Microeconometrics using Stata, STATA Press.

Cavailhes, J., Brossard, T., Foltite, J.-C., Hilal, M., Joly, D., Tourneux, F.-P., Tritz, C. and Wavresky, P.: 2009, Gis-based hedonic pricing of landscape, Environmental and Resource Economics 44, 571-590.

Chamblee, J. F., Colwell, P. F., Dehring, C. A. and Depken, C. A.: 2011, The effect of conservation activity on surrounding land prices, Land Economics 87(3), 453-472.

Chay, K. Y. and Greenstone, M.: 2005, Does air quality matter? evidence from the housing market, Journal of Political Economy 113(2), 376-424.

Day, B., Bateman, I. and Lake, I.: 2007, Beyond implicit prices: recovering theoretically consistent and transferable values for noise avoidance from a hedonic property price model, Environmental 6 Resource Economics 37(1), 211-232.

Deaton, B. J. and Vyn, R. J.: 2010, The effect of strict agricultural zoning on agricultural land values: The case of ontario's greenbelt, American Journal of Agricultural Economics 92(4), 941-955.

Ekeland, I., Heckman, J. J. and Nesheim, L.: 2004, Identification and estimation of hedonic models, Journal of Political Economy 112(S1), 60-109.

Epple, D.: 1987, Hedonic prices and implicit markets: Estimating demand and supply functions for differentiated products, Journal of Political Economy 107(August), 645-681.

Geniaux, G. and Napoleone, C.: 2008, Hedonic Methods in Housing Markets, number 5, Springer, chapter Semi-parametric tools for spatial hedonic models: An introduction to Mixed Geographically Weighted Regression and Geoadditive Models. 
Gibbons, S. and Overman, H. G.: 2012, Mostly pointless spatial econometrics?, Journal of Regional Science $\mathbf{5 2}(2), 172-191$.

Gopalakrishnan, S., Smith, M. D., Slott, J. M. and Murray, A. B.: 2011, The value of disappearing beaches: A hedonic pricing model with endogenous beach width, Journal of Environmental Economics and Management 61(3), $297-310$.

Heintzelman, M. D. and Tuttle, C. M.: 2012, Values in the wind: A hedonic analysis of wind power facilities, Land Economics 88(3), 571-588.

Hoshino, T. and Kuriyama, K.: 2010, Measuring the benefits of neighborhood park amenities: Application and comparison of spatial hedonic approaches, Environmental and Resource Economics 45(3), 429-444.

Kahn, S. and Lang, K.: 1988, Efficient estimation of structural hedonic systems, International Economic Review 29(1), 157-66.

Kelejian, H. H. and Prucha, I. R.: 2010, Specification and estimation of spatial autoregressive models with autoregressive and heteroskedastic disturbances, Journal of Econometrics 157(1), 53 - 67.

Kuminoff, N. and Pope, J. C.: 2009, Capitalization and welfare measurement in the hedonic model.

Kuminoff, N. V., Parmeter, C. F. and Pope, J. C.: 2010, Which hedonic models can we trust to recover the marginal willingness to pay for environmental amenities?, Journal of Environmental Economics and Management 60(3), 145-160.

Lesage, J. P. and Pace, R. K.: 2009, Introduction to Spatial Econometrics, Taylor and Francis Group, LLC.

McConnell, V. and Walls, M.: 2005, Assessing the non-market value of open space. Report, Ressources for the Future.

McMillen, D. P.: 2012, Perspectives on spatial econometrics: Linear smoothing with structured models, Journal of Regional Science 52(2), 192-209.

of Housing, M.: 2012, http://www.boligejer.dk/om-ejendomsdata.

Palmquist, R. B.: 2004, Property value models, Handbook of Environmental Economics, Vol. 2, Elsevier North Holland.

Palmquist, R. B.: 2005, Chapter 16 property value models, in K.-G. Mler and J. R. Vincent (eds), Valuing Environmental Changes, Vol. 2 of Handbook of Environmental Economics, Elsevier, pp. 763 - 819.

Panduro, T. E. and Veie, K. L.: 2013, Classification and valuation of urban green spaces - a hedonic house price valuation, Landscape and Urban Planning 120, 119 - 128.

Pope, J. C.: 2008, Buyer information and the hedonic: The impact of a seller disclosure on the implicit price for airport noise, Journal of Urban Economics 63(2), 498 - 516.

Rosen, S.: 1974, Hedonic prices and implicit markets: Product differentiation in pure competition, Journal of Political Economy 82(1), 34-55.

Ruppert, D.: 2002, Selecting the number of knots for penalized splines, Journal of Computational and Graphical Statistics 11, 735-757. 
Small, K. A. and Steimetz, S.: 2006, Spatial hedonics and the willingness to pay for residential amenities, Working Papers 050631, University of California-Irvine, Department of Economics.

Team, R. C.: 2012, R: A Language and Environment for Statistical Computing, R Foundation for Statistical Computing, Vienna, Austria. ISBN 3-900051-07-0.

URL: http://www.R-project.org/

Walsh, P. J., Milon, J. W. and Scrogin, D. O.: 2011, The spatial extent of water quality benefits in urban housing markets, Land Economics 87(4), 628-644.

Waltert, F. and Schlaepfer, F.: 2010, Landscape amenities and local development: A review of migration, regional economic and hedonic pricing studies, Ecological Economics 70(2), 141 - 152.

Won Kim, C., Phipps, T. T. and Anselin, L.: 2003, Measuring the benefits of air quality improvement: a spatial hedonic approach, Journal of Environmental Economics and Management 45(1), 24-39.

Wood, S. N.: 2006, Generalized Additive Models: An Introduction with R, Chapman and Hall.

Wood, S. N. and Augustin, N. H.: 2002, Gams with integrated model selection using penalized regression splines and applications to environmental modelling, Ecological Modelling 157(2-3), 157 - 177. 


\section{A Descriptive statistic}

\section{A.1 Variable description}

\begin{tabular}{|c|c|}
\hline Name & Description \\
\hline Price & The price of the property in DKK. \\
\hline Time & $\begin{array}{l}\text { The analysis period measured in days from January 1st } 2000 \text { to December } \\
\text { 31st } 2007 \text {. }\end{array}$ \\
\hline Size $(\log )$ & The natural logarithm of the size of the living area measured in square meters. \\
\hline Room $(\log )$ & The natural logarithm of the number of rooms in the house. \\
\hline Basement & The size of the Basement in square meters. \\
\hline Garden & The size of the Garden in square meters. \\
\hline Number of floors & The number of floors in the house. \\
\hline Highway & $\begin{array}{l}\text { Proximity to the nearest highway described on a scale from } 0 \text { to } 500 \text { meters } \\
\text { where } 0 \text { corresponds to being at distance of } 500 \text { meters and } 500 \text { corresponds } \\
\text { to being located on the highway. }\end{array}$ \\
\hline Large road & $\begin{array}{l}\text { Proximity to the nearest Large road described on a scale from } 0 \text { to } 100 \text { meters } \\
\text { where } 0 \text { corresponds to being at distance of } 100 \text { meters and } 100 \text { corresponds } \\
\text { to being located on the Large road. }\end{array}$ \\
\hline Railway track & $\begin{array}{l}\text { Proximity to the nearest railway track described on a scale from } 0 \text { to } 100 \\
\text { meters where } 0 \text { corresponds to being at distance of } 100 \text { meters and } 100 \\
\text { corresponds to being located on the railway track. }\end{array}$ \\
\hline Industrial area & $\begin{array}{l}\text { Proximity to the nearest industrial area described on a scale from } 0 \text { to } 500 \\
\text { meters where } 0 \text { corresponds to being at distance of } 500 \text { meters and } 500 \\
\text { corresponds to being located on the industrial area. }\end{array}$ \\
\hline Coastline & $\begin{array}{l}\text { Proximity to the coastline described on a scale from } 0 \text { to } 100 \text { meters where } 0 \\
\text { corresponds to being at distance of } 100 \text { meters and } 100 \text { corresponds to being } \\
\text { located on the coastline. }\end{array}$ \\
\hline Spatial lag: Garden & The average size of Gardens of all houses on the residential street. \\
\hline Spatial lag: Brick & $\begin{array}{l}\text { The average number of houses with the outer wall made of Brick on the } \\
\text { residential street. }\end{array}$ \\
\hline Spatial Lag: Age & The average age of all houses on the residential street. \\
\hline Spatial Lag: Tile roof & The average number of houses with a Tile roof on the residential street. \\
\hline $\begin{array}{l}\text { Spatial Lag: Renovation } \\
\text { in } 1970 \text { s }\end{array}$ & $\begin{array}{l}\text { The average number of houses which have undergone major renovation during } \\
\text { the } 1970 \text { s on the residential street. }\end{array}$ \\
\hline $\begin{array}{l}\text { Spatial Lag: Renovation } \\
\text { in 1980s }\end{array}$ & $\begin{array}{l}\text { The average number of houses which have undergone major renovation during } \\
\text { the } 1980 \text { s on the residential street. }\end{array}$ \\
\hline $\begin{array}{l}\text { Spatial Lag: Renovation } \\
\text { in 1990s }\end{array}$ & $\begin{array}{l}\text { The average number of houses which have undergone major renovation during } \\
\text { the 1990s on the residential street. }\end{array}$ \\
\hline $\begin{array}{l}\text { Spatial Lag: Renovation } \\
\text { in 2000s }\end{array}$ & $\begin{array}{l}\text { The average number of houses which have undergone major renovation during } \\
\text { the } 2000 \text { s on the residential street. }\end{array}$ \\
\hline
\end{tabular}




\begin{tabular}{|c|c|}
\hline Name & Description \\
\hline Low Basement & $\begin{array}{l}\text { Dummy variable that describes the presence of a Basement with a ceiling } \\
\text { height less than } 120 \mathrm{~cm}-1 \text { corresponds to the presence of low Basement and } \\
0 \text { corresponds to the absence of low Basement. }\end{array}$ \\
\hline Renovation 1970s & $\begin{array}{l}\text { Dummy variable that describes whether the house has undergone major } \\
\text { renovation during the 1970s. } 1 \text { corresponds to major renovations and } 0 \\
\text { corresponds to no major renovation. }\end{array}$ \\
\hline Renovation 1980s & $\begin{array}{l}\text { Dummy variable that describes whether the house has undergone major } \\
\text { renovation during the 1980s. } 1 \text { corresponds to major renovations and } 0 \\
\text { corresponds to no major renovation. }\end{array}$ \\
\hline Renovation 1990s & $\begin{array}{l}\text { Dummy variable that describes whether the house has undergone major } \\
\text { renovation during the 1990s. } 1 \text { corresponds to major renovations and } 0 \\
\text { corresponds to no major renovation. }\end{array}$ \\
\hline Renovation 2000s & $\begin{array}{l}\text { Dummy variable that describes whether the house has undergone major } \\
\text { renovation during the } 2000 \text { s before the house is sold. } 1 \text { corresponds to major } \\
\text { renovations and } 0 \text { corresponds to no renovation. }\end{array}$ \\
\hline Renovation after & $\begin{array}{l}\text { Dummy variable that describes whether the house has undergone major } \\
\text { renovation after it was sold. } 1 \text { corresponds to major renovations and } 0 \\
\text { corresponds to no renovation. }\end{array}$ \\
\hline Built before 1927 & $\begin{array}{l}\text { Dummy variable that describes whether the house was built before } 1927.1 \\
\text { corresponds to being built before } 1927 \text { and } 0 \text { corresponds to being built after } \\
1927 \text {. }\end{array}$ \\
\hline $\begin{array}{l}\text { Built between } 1927 \text { and } \\
1939\end{array}$ & $\begin{array}{l}\text { Dummy variable that describes whether the house was built between } 1927 \\
\text { and 1939. } 1 \text { corresponds to being built between } 1927 \text { and } 1939 \text { and } 0 \\
\text { corresponds to not being built between } 1927 \text { and } 1939 \text {. }\end{array}$ \\
\hline $\begin{array}{l}\text { Built between } 1939 \text { and } \\
1955\end{array}$ & $\begin{array}{l}\text { Dummy variable that describes whether the house was built between } 1939 \\
\text { and } 1955.1 \text { corresponds to being built between } 1939 \text { and } 1955 \text { and } 0 \\
\text { corresponds to not being built between } 1939 \text { and } 1955 \text {. }\end{array}$ \\
\hline $\begin{array}{l}\text { Built between } 1955 \text { and } \\
1975\end{array}$ & $\begin{array}{l}\text { Dummy variable that describes whether the house was built between } 1955 \\
\text { and } 1975.1 \text { corresponds to being built between } 1955 \text { and } 1975 \text { and } 0 \\
\text { corresponds to not being built between } 1955 \text { and } 1975 \text {. }\end{array}$ \\
\hline $\begin{array}{l}\text { Built between } 1975 \text { and } \\
1999\end{array}$ & $\begin{array}{l}\text { Dummy variable that describes whether the house was built between } 1975 \\
\text { and 1999. } 1 \text { corresponds to being built between } 1975 \text { and } 1999 \text { and } 0 \\
\text { corresponds to not being built between } 1975 \text { and } 1999 .\end{array}$ \\
\hline Brick & $\begin{array}{l}\text { Dummy variable that describes whether the outer wall of the house is made of } \\
\text { Bricks. } 1 \text { corresponds to the outer wall consists of Bricks and } 0 \text { corresponds } \\
\text { to the outer wall consists of other materials. }\end{array}$ \\
\hline Tile roof & $\begin{array}{l}\text { Dummy variable that describes whether the roof is made of tile. } 1 \\
\text { corresponds to being made of tile and } 0 \text { corresponds to not made of tile. }\end{array}$ \\
\hline Fiber board roof & $\begin{array}{l}\text { Dummy variable that describes whether the roof is made of fiber board. } 1 \\
\text { corresponds to being made of fiber board and } 0 \text { corresponds to not made of } \\
\text { fiber board. }\end{array}$ \\
\hline
\end{tabular}




\begin{tabular}{|c|c|}
\hline Name & Description \\
\hline Terraced house & $\begin{array}{l}\text { Dummy variable that describes whether house is a single family house or a } \\
\text { terraced house. } 1 \text { corresponds to terraced house and } 0 \text { corresponds to single } \\
\text { family house. }\end{array}$ \\
\hline Hasseris & $\begin{array}{l}\text { Dummy variable that describes whether the house is located in Hasseris. } 1 \\
\text { corresponds to being located in Hasseris and } 0 \text { corresponds to not being } \\
\text { located in Hasseris. Hasseris is the high income area in Aalborg. }\end{array}$ \\
\hline Park & $\begin{array}{l}\text { Proximity to the nearest Park described on a scale from } 0 \text { to } 600 \text { meters where } \\
0 \text { corresponds to being at distance of } 600 \text { meters and } 600 \text { corresponds to being } \\
\text { located on the boarder of the Park. Proximity is measured in } 100 \text { meters. }\end{array}$ \\
\hline Nature & $\begin{array}{l}\text { Proximity to the nearest nature areas described on a scale from } 0 \text { to } 600 \\
\text { meters where } 0 \text { corresponds to being at distance of } 600 \text { meters and } 600 \\
\text { corresponds to being located on the boarder of the nature area. Proximity is } \\
\text { measured in steps of } 100 \text { meters. }\end{array}$ \\
\hline Lake & $\begin{array}{l}\text { Proximity to the nearest Lake area described on a scale from } 0 \text { to } 600 \text { meters } \\
\text { where } 0 \text { corresponds to being at distance of } 600 \text { meters and } 600 \text { corresponds } \\
\text { to being located on the boarder of the nature area. Proximity is measured in } \\
\text { steps of } 100 \text { meters. }\end{array}$ \\
\hline Common area size & The size of the nearest Common area measured in Hectares. \\
\hline Sport field & $\begin{array}{l}\text { Proximity to the nearest Sport field described on a scale from } 0 \text { to } 300 \text { meters } \\
\text { where } 0 \text { corresponds to being at distance of } 300 \text { meters and } 300 \text { corresponds } \\
\text { to being located on the boarder of the Sport field. Proximity is measured in } \\
100 \text { meters. }\end{array}$ \\
\hline Agriculture field & $\begin{array}{l}\text { Proximity to the nearest Agriculture field described on a scale from } 0 \text { to } 300 \\
\text { meters where } 0 \text { corresponds to being at distance of } 300 \text { meters and } 300 \\
\text { corresponds to being located on the boarder of the Agriculture field. } \\
\text { Proximity is measured in steps of } 100 \text { meters. }\end{array}$ \\
\hline Scrapland & $\begin{array}{l}\text { Proximity to the nearest Scrapland described on a scale from } 0 \text { to } 300 \text { meters } \\
\text { where } 0 \text { corresponds to being at distance of } 300 \text { meters and } 300 \text { corresponds } \\
\text { to being located on the boarder of the Scrapland. Proximity is measured in } \\
100 \text { meters. }\end{array}$ \\
\hline Churchyard & $\begin{array}{l}\text { Proximity to the nearest churchyard described on a scale from } 0 \text { to } 300 \text { meters } \\
\text { where } 0 \text { corresponds to being at distance of } 300 \text { meters and } 300 \text { corresponds } \\
\text { to being located on the boarder of churchyard. Proximity is measured in steps } \\
\text { of } 100 \text { meters. }\end{array}$ \\
\hline
\end{tabular}

\section{A.2 Descriptive statistics - Continuous Variables}

\begin{tabular}{|l|l|l|l|l|l|l|}
\hline Variable & Min & X1st.Q. & Median & Mean & X3rd.Q. & Max \\
\hline Price & 250000 & 1020000 & 1300000 & 1449000 & 1680000 & 9000000 \\
\hline Time & 1 & 774 & 1514 & 1474 & 2179 & 2918 \\
\hline Garden & 0 & 496 & 736 & 681.400000 & 848 & 3538 \\
\hline
\end{tabular}




\begin{tabular}{|c|c|c|c|c|c|c|}
\hline Variable & Min & X1st.Q. & Median & Mean & X3rd.Q. & Max \\
\hline Size $(\log )$ & 4.025000 & 4.682000 & 4.875000 & 4.877000 & 5.063000 & 6.038000 \\
\hline Room (log) & 0 & 1.386000 & 1.609000 & 1.508000 & 1.609000 & 2.708000 \\
\hline Basement & 0 & 0 & 0 & 22.700000 & 44 & 210 \\
\hline Number of floors & 1 & 1 & 1 & 1.100000 & 1 & 3 \\
\hline Highway & 0 & 0 & 0 & 51.360000 & 13.520000 & 472.360000 \\
\hline Large road & 0 & 0 & 0 & 0.190100 & 0 & 1 \\
\hline Railway track & 0 & 0 & 0 & 1.098000 & 0 & 87.300000 \\
\hline Industrial area & 0 & 0 & 130.800000 & 162.900000 & 308 & 500 \\
\hline Coastline & 1.071000 & 10.869000 & 20.973000 & 24.273000 & 37.088000 & 66.036000 \\
\hline Spatial lag: Garden & 0 & 583.100000 & 750 & 707.900000 & 858.700000 & 2200 \\
\hline Spatial lag: Brick & 0.114300 & 0.937500 & 0.990200 & 0.951900 & 1 & 1 \\
\hline Spatial Lag: Age & 1850 & 1942 & 1960 & 1957 & 1970 & 2009 \\
\hline Spatial Lag: Tile roof & 0 & 0.037040 & 0.120000 & 0.218530 & 0.322030 & 1 \\
\hline $\begin{array}{l}\text { Spatial Lag: Renovation } \\
\text { in } 1970 \text { s }\end{array}$ & 0 & 0.016390 & 0.083330 & 0.102930 & 0.153850 & 1 \\
\hline $\begin{array}{l}\text { Spatial Lag: Renovation } \\
\text { in } 1980 \text { s }\end{array}$ & 0 & 0.034480 & 0.083330 & 0.093270 & 0.134020 & 1 \\
\hline $\begin{array}{l}\text { Spatial Lag: Renovation } \\
\text { in 1990s }\end{array}$ & 0 & 0.015500 & 0.061860 & 0.072030 & 0.106670 & 1 \\
\hline $\begin{array}{l}\text { Spatial Lag: Renovation } \\
\text { in } 2000 \text { s }\end{array}$ & 0 & 0 & 0.043480 & 0.061740 & 0.086960 & 1 \\
\hline Park & 0 & 0 & 0 & 0.916200 & 1.461000 & 5.963000 \\
\hline Nature & 0 & 0 & 1.086000 & 1.754000 & 3.334000 & 6 \\
\hline Common area size & 0 & 0 & 0.927300 & 1.263000 & 2.430000 & 5.473000 \\
\hline Lake & 0 & 0 & 0 & 0.5908 & 0 & 6 \\
\hline Sport field & 0 & 0 & 0 & 0.514300 & 0.878300 & 2.945000 \\
\hline Agriculture field & 0 & 0 & 0 & 0.191200 & 0 & 2.921000 \\
\hline Scrapland & 0 & 0 & 0 & 0.560400 & 1.050000 & 2.976000 \\
\hline Churchyard & 0 & 0 & 0 & 0.157800 & 0 & 2.931000 \\
\hline
\end{tabular}

\section{A.3 Descriptive statistics - dummy variables}

\begin{tabular}{|c|c|c|}
\hline Variable & Variable.0 & Variable.1 \\
\hline Low Basement & 5618 & 695 \\
\hline Renovation 1970s & 5734 & 579 \\
\hline Renovation 1980s & 5774 & 539 \\
\hline Renovation 1990s & 5948 & 365 \\
\hline Renovation 2000s & 6226 & 87 \\
\hline Renovation after & 5895 & 418 \\
\hline Built before 1927 & 5368 & 945 \\
\hline
\end{tabular}




\begin{tabular}{|c|c|c|}
\hline Variable & Variable.0 & Variable.1 \\
\hline $\begin{array}{c}\text { Built between 1927 and } \\
1939\end{array}$ & 5605 & 708 \\
\hline $\begin{array}{c}\text { Built between 1939 and } \\
1955\end{array}$ & 5604 & 709 \\
\hline $\begin{array}{c}\text { Built between 1955 and } \\
1975\end{array}$ & 3761 & 2552 \\
\hline $\begin{array}{c}\text { Built between 1975 and } \\
1999\end{array}$ & 5193 & 1120 \\
\hline Brick & 297 & 6016 \\
\hline Tile roof & 4903 & 1410 \\
\hline Fiber board roof & 2716 & 3597 \\
\hline Terraced house & 5135 & 1178 \\
\hline Hasseris & 4953 & 1360 \\
\hline
\end{tabular}




\section{B Full model estimation}

\section{B.1 GLM - Linear non-spatial model}

Tab. 12: Generalized Linear model

\begin{tabular}{|c|c|c|c|c|}
\hline & Estimate & Std. Error & $\mathrm{z}$ value & $\operatorname{Pr}(>|z|)$ \\
\hline (Intercept) & 8.503690 & 0.597222 & 14.238733 & 0.000000 \\
\hline Garden & 0.000177 & 0.000017 & 10.730968 & 0.000000 \\
\hline Size $(\log )$ & 0.522822 & 0.018421 & 28.381871 & 0.000000 \\
\hline Room (log) & -0.000636 & 0.015259 & -0.041711 & 0.966729 \\
\hline Basement & 0.001143 & 0.000084 & 13.571994 & 0.000000 \\
\hline Low basement & 0.088707 & 0.009977 & 8.890984 & 0.000000 \\
\hline Number of floors & -0.012809 & 0.011377 & -1.125858 & 0.260226 \\
\hline Renovation 1970s & 0.000210 & 0.008647 & 0.024293 & 0.980619 \\
\hline Renovation 1980s & 0.025942 & 0.008942 & 2.901125 & 0.003718 \\
\hline Renovation 1990s & 0.068039 & 0.010756 & 6.325475 & 0.000000 \\
\hline Renovation 2000s & 0.131813 & 0.021528 & 6.122813 & 0.000000 \\
\hline Renovation after & -0.141583 & 0.013475 & -10.507057 & 0.000000 \\
\hline Built before 1927 & 0.789417 & 0.032010 & 24.661863 & 0.000000 \\
\hline Built between 1927 and 1939 & 0.829979 & 0.030961 & 26.807278 & 0.000000 \\
\hline etween 1939 and 1955 & 0.812930 & 0.030418 & 26.725557 & 0.000000 \\
\hline Built between 1955 and 1975 & 0.860642 & 0.028214 & 30.504192 & 0.000000 \\
\hline reen 1975 and 1999 & 1.016630 & 0.026994 & 37.661832 & 0.000000 \\
\hline Brick & $0.0^{\prime}$ & 0.013950 & 5.649174 & 0.000000 \\
\hline Tile roof & 0.0 & 0.010555 & 2.936875 & 0.003315 \\
\hline Fiber board roof & -0.05 & 0.007311 & -7.904 & 0.000000 \\
\hline Higl & -0.0 & 0028 & -3.74 & 0.000179 \\
\hline Large & -0.0 & 0.007372 & -4.372372 & 0.000012 \\
\hline Railway & -0.0 & 0.000306 & -0.710 & 0.477607 \\
\hline Industrial & -0.0 & 0.000021 & -2.95 & 0.00 \\
\hline Coas & 0.0 & 0403 & 13.661 & 0.000000 \\
\hline Terraced house & 0.012938 & 0.012402 & 1.043246 & 0.296834 \\
\hline Hasseris & 0.239 & 0.009459 & 25.367792 & 0.000000 \\
\hline Spatial lag: Garden & -0.000009 & 0.000019 & -0.481783 & 0.629960 \\
\hline Spatial lag: Brick & 0.167 & 0.035322 & 4.747998 & 0.000002 \\
\hline Spatial lag: Age & 0.000860 & 0.000293 & 2.932759 & 0.003360 \\
\hline Spatial lą & 0.068 & & $4.02 !$ & 0.000056 \\
\hline Spatial lag: Renovation 1970s & 0.064 & 0.035700 & 1.807867 & 0.070627 \\
\hline Spatial lag: Renovation 1980s & 0.106024 & 0.037897 & 2.797727 & 0.005146 \\
\hline Spatial lag: Renovation 1990s & 0.141692 & 0.043758 & 3.238076 & 0.001203 \\
\hline Spatial lag: Renovation 2000s & 0.1236 & 0.038286 & 3.230375 & 0.001236 \\
\hline City center & 0.000099 & 0.000005 & 19.192674 & 0.000000 \\
\hline Park $^{2}$ & 0.001831 & 0.000458 & 4.000440 & 0.000063 \\
\hline Nature $^{2}$ & 0.000739 & 0.000339 & 2.182425 & 0.029078 \\
\hline Lake $^{2}$ & 0.000132 & 0.000496 & 0.266916 & 0.789534 \\
\hline Scrapland ${ }^{2}$ & -0.006646 & 0.001703 & -3.903028 & 0.000095 \\
\hline Sport field $^{2}$ & 0.000654 & 0.001647 & 0.396990 & 0.691375 \\
\hline Churchyard $^{2}$ & -0.000395 & 0.002764 & -0.142838 & 0.886418 \\
\hline Agriculture field ${ }^{2}$ & -0.003342 & 0.002381 & -1.403707 & 0.160406 \\
\hline Common area & -0.004235 & 0.001436 & -2.948557 & 0.003193 \\
\hline
\end{tabular}




\section{B.2 Spatial Fixed effect model}

Tab. 13: Spatial fixed effect model

\begin{tabular}{rrrrr}
\hline & Estimate & Std. Error & $\mathrm{z}$ value & $\mathrm{Pr}(>|\mathrm{z}|)$ \\
\hline (Intercept) & 9.210188 & 1.378333 & 6.682123 & 0.000000 \\
Garden & 0.000176 & 0.000026 & 6.728654 & 0.000000 \\
Size (log) & 0.516506 & 0.028923 & 17.858248 & 0.000000 \\
Room (log) & 0.001003 & 0.017259 & 0.058094 & 0.953674 \\
Basement & 0.001118 & 0.000092 & 12.140897 & 0.000000 \\
Low basement & 0.088978 & 0.010552 & 8.432518 & 0.000000 \\
Number of floors & -0.012378 & 0.021753 & -0.569015 & 0.569346 \\
Renovation 1970s & 0.001294 & 0.009841 & 0.131444 & 0.895424 \\
Renovation 1980s & 0.027830 & 0.010154 & 2.740878 & 0.006128 \\
Renovation 1990s & 0.066238 & 0.013634 & 4.858306 & 0.000001 \\
Renovation 2000s & 0.135417 & 0.028856 & 4.692878 & 0.000003 \\
Renovation after & -0.143725 & 0.012471 & -11.524720 & 0.000000 \\
Built before 1927 & 0.762143 & 0.065237 & 11.682602 & 0.000000 \\
Built between 1927 and 1939 & 0.802979 & 0.062859 & 12.774212 & 0.000000 \\
Built between 1939 and 1955 & 0.784160 & 0.070671 & 11.095945 & 0.000000 \\
Built between 1955 and 1975 & 0.830159 & 0.067947 & 12.217670 & 0.000000 \\
Built between 1975 and 1999 & 0.987368 & 0.062554 & 15.784365 & 0.000000 \\
Brick & 0.078455 & 0.013975 & 5.613848 & 0.000000 \\
Tile roof & 0.032752 & 0.011844 & 2.765370 & 0.005686 \\
Agriculture field ${ }^{2}$ & -0.006475 & 0.005482 & -1.181123 & 0.237554 \\
Common area & -0.004854 & 0.002599 & -1.868073 & 0.061752
\end{tabular}




\section{B.3 SEM - spatial error model}

Tab. 14: Spatial error model

\begin{tabular}{|c|c|c|c|c|}
\hline & Estimate & Std. Error & $\mathrm{z}$ value & $\operatorname{Pr}(>|z|)$ \\
\hline (Intercept) & 8.565638 & 0.600863 & 14.255557 & 0 \\
\hline Garden & 0.000190 & 0.000013 & 14.961683 & 0 \\
\hline Size (log) & 0.470979 & 0.016441 & 28.646423 & 0 \\
\hline Room (log) & 0.007191 & 0.014577 & 0.493313 & 0.621791 \\
\hline Basement & 0.001030 & 0.000088 & 11.770959 & 0 \\
\hline Low basement & 0.082379 & 0.009382 & 8.780342 & 0 \\
\hline Number of floors & 0.006436 & 0.012564 & 0.512248 & 0.608478 \\
\hline Renovation 1970s & 0.001895 & 0.009533 & 0.198771 & 0.842442 \\
\hline Renovation 1980s & 0.029662 & 0.009649 & 3.074133 & 0.002111 \\
\hline Renovation 1990s & 0.068817 & 0.011429 & 6.021188 & 0 \\
\hline Renovation 2000s & 0.137674 & 0.022252 & 6.186991 & 0 \\
\hline Renovation after & -0.142236 & 0.011334 & -12.549990 & 0 \\
\hline Built before 1927 & 0.737451 & 0.022706 & 32.478629 & 0 \\
\hline Built between 1927 and 1939 & 0.780255 & 0.022522 & 34.643855 & 0 \\
\hline Built between 1939 and 1955 & 0.757792 & 0.022209 & 34.120598 & 0 \\
\hline Built between 1955 and 1975 & 0.799521 & 0.020256 & 39.471132 & 0 \\
\hline Built between 1975 and 1999 & 0.972320 & 0.020173 & 48.198109 & 0 \\
\hline Brick & 0.081458 & 0.013908 & 5.856929 & 0 \\
\hline Tile roof & 0.040255 & 0.009400 & 4.282475 & 0.000018 \\
\hline Fiber board roof & -0.045686 & 0.007501 & -6.090953 & 0 \\
\hline Highway & -0.000126 & 0.000049 & -2.575456 & 0.010011 \\
\hline Large road & -0.030382 & 0.009622 & -3.157504 & 0.001591 \\
\hline Railway tracks & -0.000460 & 0.000470 & -0.978550 & 0.327803 \\
\hline Industrial area & -0.000053 & 0.000036 & -1.460393 & 0.144182 \\
\hline Coastline & 0.006270 & 0.000680 & 9.215936 & 0 \\
\hline Terraced house & -0.000895 & 0.011838 & -0.075590 & 0.939746 \\
\hline Hasseris & 0.253914 & 0.015441 & 16.444185 & 0 \\
\hline Spatial lag: Garden & -0.000042 & 0.000022 & -1.970207 & 0.048815 \\
\hline Spatial lag: Brick & 0.085943 & 0.047776 & 1.798883 & 0.072037 \\
\hline Spatial lag: Age & 0.000986 & 0.000296 & 3.329734 & 0.000869 \\
\hline Spatial lag: Tile roof & 0.046096 & 0.020203 & 2.281570 & 0.022515 \\
\hline Spatial lag: Renovation 1970s & 0.069076 & 0.040271 & 1.715284 & 0.086293 \\
\hline Spatial lag: Renovation 1980s & 0.130640 & 0.044471 & 2.937637 & 0.003307 \\
\hline Spatial lag: Renovation 1990s & 0.068966 & 0.049750 & 1.386259 & 0.165668 \\
\hline Spatial lag: Renovation 2000s & 0.073930 & 0.045307 & 1.631762 & 0.102730 \\
\hline City center & 0.000108 & 0.000008 & 13.133140 & 0 \\
\hline Park $^{2}$ & 0.001881 & 0.000737 & 2.552715 & 0.010689 \\
\hline Nature $^{2}$ & 0.000994 & 0.000527 & 1.884669 & 0.059475 \\
\hline Lake $^{2}$ & 0.000539 & 0.000807 & 0.668571 & 0.503769 \\
\hline Scrapland $^{2}$ & -0.005306 & 0.002466 & -2.151599 & 0.031429 \\
\hline Sport field $^{2}$ & 0.000088 & 0.002408 & 0.036402 & 0.970962 \\
\hline Churchyard $^{2}$ & 0.003795 & 0.004053 & 0.936345 & 0.349095 \\
\hline Agriculture field ${ }^{2}$ & -0.003970 & 0.003731 & -1.064000 & 0.287329 \\
\hline Common area & -0.003597 & 0.001442 & -2.494973 & 0.012597 \\
\hline
\end{tabular}




\section{B.4 GAM - Generalized additive model}

Tab. 15: Generalized Additive Model

\begin{tabular}{|c|c|c|c|c|}
\hline & Estimate & Std. Error & $\mathrm{t}$ value & $\operatorname{Pr}(>|t|)$ \\
\hline (Intercept) & 10.441177 & 0.545457 & 19.142058 & 0.000000 \\
\hline Garden & 0.000176 & 0.000012 & 14.156827 & 0.000000 \\
\hline Size $(\log )$ & 0.490631 & 0.016404 & 29.909151 & 0.000000 \\
\hline Room (log) & 0.008223 & 0.014679 & 0.560183 & 0.575375 \\
\hline Basement & 0.001047 & 0.000086 & 12.106932 & 0.000000 \\
\hline Low basement & 0.085165 & 0.009387 & 9.072418 & 0.000000 \\
\hline Number of floors & -0.012972 & 0.011059 & -1.172941 & 0.240864 \\
\hline Renovation 1970s & 0.001449 & 0.009838 & 0.147279 & 0.882917 \\
\hline Renovation 1980s & 0.025724 & 0.009869 & 2.606706 & 0.009164 \\
\hline Renovation 1990s & 0.067982 & 0.011771 & 5.775617 & 0.000000 \\
\hline Renovation 2000s & 0.127254 & 0.022827 & 5.574606 & 0.000000 \\
\hline Renovation after & -0.144840 & 0.011630 & -12.454045 & 0.000000 \\
\hline Built before 1927 & 0.743429 & 0.021561 & 34.480999 & 0.000000 \\
\hline Built between 1927 and 1939 & 0.791304 & 0.021170 & 37.379191 & 0.000000 \\
\hline Built between 1939 and 1955 & 0.763521 & 0.020649 & 36.976943 & 0.000000 \\
\hline Built between 1955 and 1975 & 0.798661 & 0.018605 & 42.927178 & 0.000000 \\
\hline Built between 1975 and 1999 & 0.975576 & 0.017870 & 54.594239 & 0.000000 \\
\hline Brick & 0.080204 & 0.013834 & 5.797618 & 0.000000 \\
\hline Tile roof & 0.030475 & 0.009404 & 3.240631 & 0.001199 \\
\hline Fiber board roof & -0.051833 & 0.007290 & -7.110271 & 0.000000 \\
\hline Highway & -0.000023 & 0.000039 & -0.585887 & 0.557973 \\
\hline Large road & -0.040075 & 0.007526 & -5.324475 & 0.000000 \\
\hline Railway tracks & 0.000051 & 0.000386 & 0.131111 & 0.895692 \\
\hline Industrial area & -0.000068 & 0.000029 & -2.366173 & 0.018003 \\
\hline Coastline & -0.020387 & 0.005779 & -3.527591 & 0.000422 \\
\hline Terraced house & -0.004910 & 0.010804 & -0.454473 & 0.649504 \\
\hline Hasseris & 0.006180 & 0.032625 & 0.189436 & 0.849757 \\
\hline Spatial lag: Garden & -0.000045 & 0.000019 & -2.399811 & 0.016433 \\
\hline Spatial lag: Brick & 0.090979 & 0.037178 & 2.447140 & 0.014427 \\
\hline Spatial lag: Age & 0.000565 & 0.000262 & 2.157091 & 0.031037 \\
\hline Spatial lag: Tile roof & -0.009284 & 0.018046 & -0.514484 & 0.606932 \\
\hline Spatial lag: Renovation 1970s & 0.024150 & 0.035625 & 0.677891 & 0.497866 \\
\hline Spatial lag: Renovation 1980s & 0.082939 & 0.038211 & 2.170564 & 0.030002 \\
\hline Spatial lag: Renovation 1990s & 0.073418 & 0.044315 & 1.656743 & 0.097622 \\
\hline Spatial lag: Renovation 2000s & 0.065418 & 0.039060 & 1.674832 & 0.094017 \\
\hline Park $^{2}$ & 0.002296 & 0.000561 & 4.092079 & 0.000043 \\
\hline Nature $^{2}$ & 0.001474 & 0.000441 & 3.344189 & 0.000830 \\
\hline Lake $^{2}$ & 0.001467 & 0.000762 & 1.926020 & 0.054147 \\
\hline Scrapland ${ }^{2}$ & -0.007624 & 0.001867 & -4.082655 & 0.000045 \\
\hline Sport field ${ }^{2}$ & 0.001363 & 0.001632 & 0.835348 & 0.403554 \\
\hline Churchyard $^{2}$ & 0.005837 & 0.002665 & 2.190105 & 0.028554 \\
\hline Agriculture field ${ }^{2}$ & -0.003020 & 0.002784 & -1.084734 & 0.278082 \\
\hline Common area & -0.002167 & 0.001237 & -1.752392 & 0.079756 \\
\hline
\end{tabular}

